\title{
INTEGRATION OF MEDICAL AND DENTAL SERVICES: CASE STUDY OF THE TERRY REILLY HEALTH SERVICES LATAH CLINIC EXPERIENCE
}

\author{
By \\ Kylie B. Pace
}

\author{
A thesis \\ submitted in partial fulfillment \\ of the requirements for the degree of \\ Master of Health Science \\ Boise State University
}

August 2017 
(C)2017

Kylie B. Pace

ALL RIGHTS RESERVED 


\section{BOISE STATE UNIVERSITY GRADUATE COLLEGE \\ DEFENSE COMMITTEE AND FINAL READING APPROVALS}

of the thesis submitted by

Kylie B. Pace

Thesis Title: Integration of Medical and Dental Services: Case Study of the Terry Reilly Health Services Latah Clinic Experience

Date of Final Oral Examination: 13 June 2017

The following individuals read and discussed the thesis submitted by student Kylie B. Pace, and they evaluated her presentation and response to questions during the final oral examination. They found that the student passed the final oral examination.

Sarah E. Toevs, Ph.D.

Caile E. Spear, Ph.D.

Jeannie McCarthy-Jaggi, M.H.S.
Chair, Supervisory Committee

Member, Supervisory Committee

Member, Supervisory Committee

The final reading approval of the thesis was granted by Sarah E. Toevs, Ph.D., Chair of the Supervisory Committee. The thesis was approved by the Graduate College. 


\section{ACKNOWLEDGEMENTS}

I would like to thank Tami Fife, for her support and encouragement during this study and allowing me the opportunity to work with Terry Reilly Health Services. It is my hope that integrated medical-dental practices will someday be the norm. I would also like to thank my supervisory committee: Dr. Sarah Toevs, Dr. Caile Spear and Jeannie McCarthy-Jaggi; for their guidance and assistance in completing this thesis. A whirlwind of emotions was experienced during this project, but I cannot be prouder of the product thanks to my outstanding committee. Finally, I would like to thank Tyler, Tawnie, Darin, Rhonda and Jaren for their support and pushing me to do my best in everything I do. 


\begin{abstract}
Although evidence has demonstrated the link between oral and overall health, full integration of medical and dental services in practice is rare in the United States. The current research was designed to describe the development and implementation of the Terry Reilly Health Services (TRHS) Latah Medical-Dental-Behavioral Health integrated clinic (Latah Clinic). Data was collected through structured interviews with a purposive sample of employees from TRHS; observations of a Latah Clinic care team meeting; an environmental scan of facility space; and an analysis of intake forms used at the Latah Clinic. Seven employees from TRHS were invited to participate in structured interviews. Five participants completed the interviews, three face-to-face and two via e-mail. Checklists were developed to document evidence of integration during the Latah Clinic care team meeting, environmental scan and analysis of intake forms.

The findings from this study suggest that the Latah Clinic is fully integrated and demonstrates high levels of collaboration. The clinic would like to continue to grow and improve, therefore, suggestions to aide in this endeavor were provided. Study limitations such as small sample size and the lack of information from the perspective of the patient must be considered when interpreting the findings.

TRHS Latah Medical-Dental-Behavioral Health Clinic is a rarity in the United States. The strategies used in the TRHS integration process serve as a model for other practices and health care organizations as they evolve toward becoming patient-centered medical-dental homes.
\end{abstract}




\section{TABLE OF CONTENTS}

ACKNOWLEDGMENTS .................................................... iv

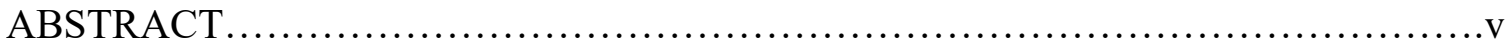

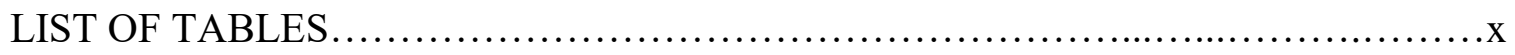

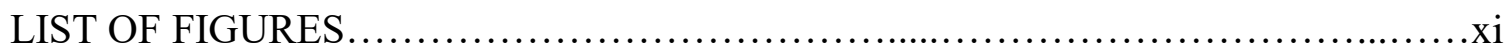

LIST OF ABBREVIATIONS ................................................

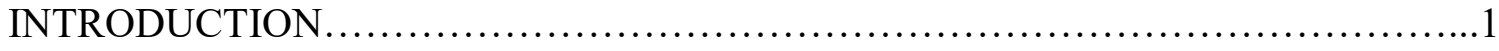

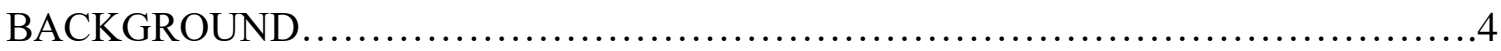

PCM-DH........................................................4

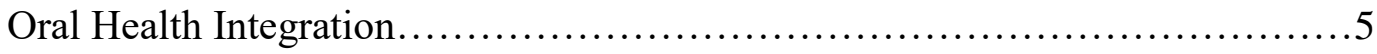

Ideal Oral Health Care System...................................5

Integration into Primary Care System.............................6

Potential Impact of Oral Health Integration.........................6

Improve Health Outcomes and Reduce Health Care Costs..........6

Improve Physical Access and Patient-Specific Barriers............

Models of Oral Heal Integration..................................8

Levels of Collaboration/Integration...............................10

Characteristics of a Fully-Integrated System....................13

Medical and Dental Professional's Perceptions of Integration.................. 14

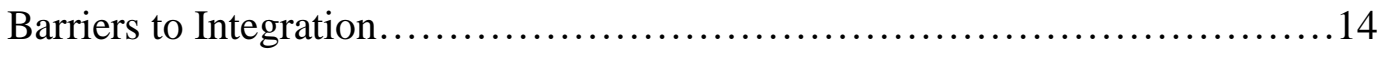

Terry Reilly Health Services........................................... 16 
The TRHS Latah Medical-Dental-Behavioral Health Clinic. ...

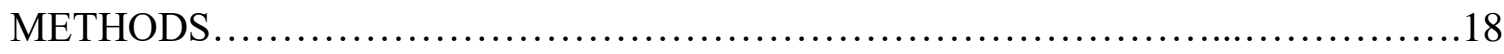

Key Informant Recruitment...............................................18

Key Informant Tools....................................................... 19

Latah Clinic Key Informant Tool....................................19

TRHS Leadership Key Informant Tool..............................20

Latah Clinic Care Team Meeting Observations..............................20

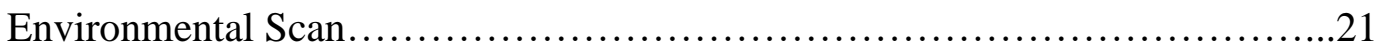

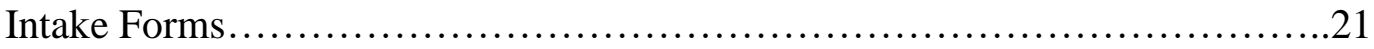

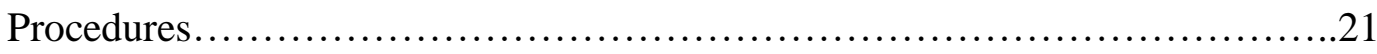

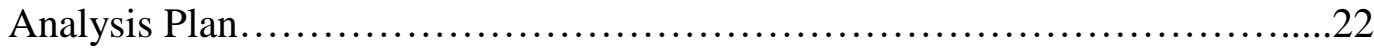

Latah Clinic Key Informant Tool...................................22

TRHS Leadership Key Informant Tool...............................23

Latah Clinic Care Team Meeting Analysis..............................23

Environmental Scan Analysis......................................23

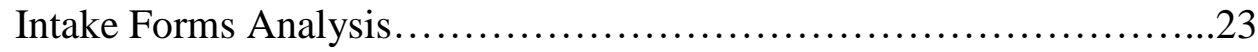

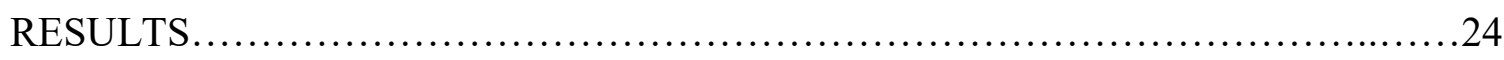

Latah Clinic Key Informants...........................................24

Background Information.......................................... 24

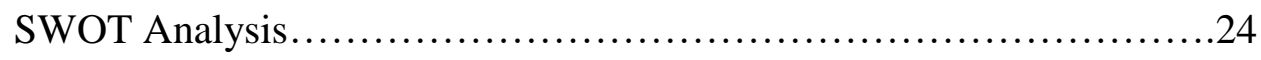

Recommendations from Key Informants............................26

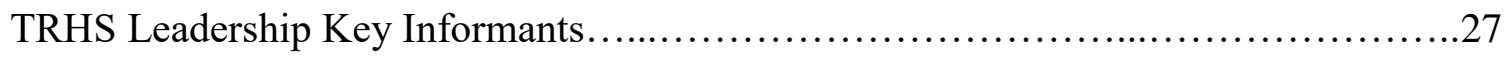

Integration Level...............................................27 
Perceptions of Latah Clinic Future................................29

Latah Care Team Meeting Observations...................................29

Environmental Scan.................................................. 30

Intake Forms.................................................... 34

Dental...................................................... 34

Behavioral Health.............................................. 34

Patient Registration.............................................. 35

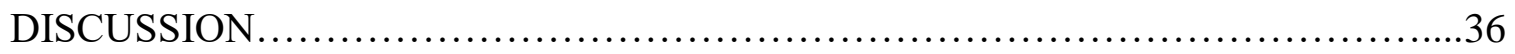

Study Limitations.................................................. 37

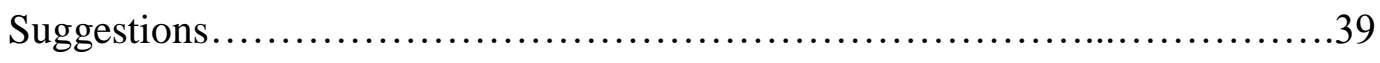

CONCLUSIONS .........................................................4

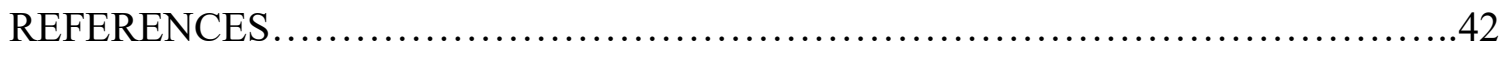

APPENDIX A........................................................... 48

Recruitment message................................................49

APPENDIX B......................................................... 50

Informed Consent Form Text.........................................51

APPENDIX C........................................................... 54

Latah Clinic Key Informant Interview Script............................55

APPENDIX D............................................................ 56

TRHS Leadership Key Informant Interview Script.............................57

APPENDIX E............................................................. 58

Latah Clinic Care Team Meeting Observations Checklist.....................59

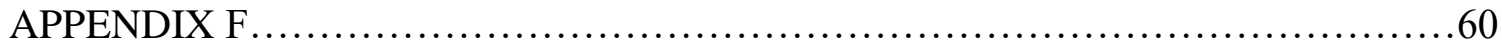


Latah Clinic Care Team Meeting Agenda.................................61

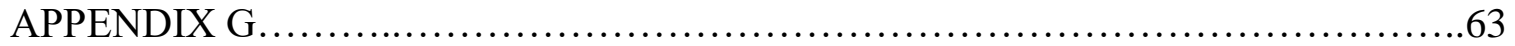

Environmental Scan Checklist..........................................64

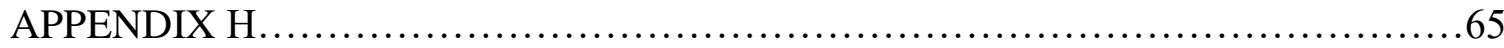

Intake Forms Checklist.............................................66

APPENDIX I.............................................................67

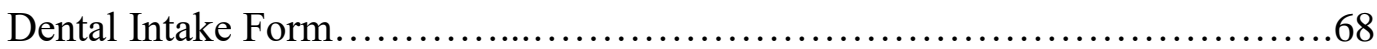

APPENDIX J........................................................... 72

Behavioral Health Intake Form...........................................73

APPENDIX K.......................................................... 79

Patient Registration Form............................................. 80

APPENDIX L........................................................... 82

IRB Exemption Letter............................................... 83 


\section{LIST OF TABLES}

Table 1 The Five Potential Models for Medical-Dental Integration................10

Table 2 SWOT Analysis from Latah Clinic Key Informant Interviews.........25-26

Table 3 Integration Models Utilized at the Latah Clinic......................................27 


\section{LIST OF FIGURES}

Figure 1.

Figure 2.

Figure $3 \& 4$.

Figure 5.

Figure 6.

Figure 7.

Figure 8.

Figure 9.
The Six Levels of Collaboration/Integration. 12

Outside of the Latah Clinic.....................................31

Latah Clinic Waiting Room....................................32

Diagram of Latah Clinic....................................... 32

Behavioral Health Consult Room..................................33

Medical Procedure Room......................................33

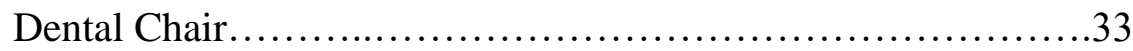

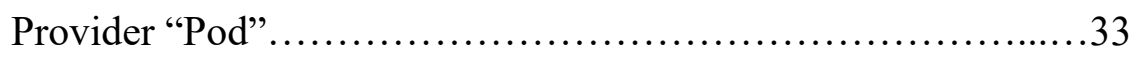




\section{LIST OF ABBREVIATIONS}

AAFP

ADA

CEO

CIHS

$\mathrm{COO}$

EHR

FQHCs

HRSA

IHS

ISU

NMCOHP

NNOHA

PCM-DH

PCMH

PI

SAMHSA

TRHS

VA

WHO
American Academy of Family Practitioners

American Dental Association

Chief Executive Officer

Center for Integrated Health Solutions

Chief Operating Officer

Electronic Health Record

Federally Qualified Health Centers

Health Resources and Services Administration

Indian Health Services

Idaho State University

National Maternal and Child Oral Health Policy Center

National Network for Oral Health Access

Patient-Centered Medical-Dental Home

Patient-Centered Medical Home

Principal Investigator

Substance Abuse and Mental Health Services Administration

Terry Reilly Health Services

Veterans Administration

World Health Organization 


\section{INTRODUCTION}

In 2007, the Joint Principles of the Patient-Centered Medical Home (PCMH) was developed by The American Academy of Physicians, American Academy of Pediatrics, American College of Physicians, and American Osteopathic Association (American Academy of Physicians (AAFP), n.d. b). This document defined the PCMH as an approach to provide comprehensive primary care for patients of all ages through facilitated partnerships between patients, their physicians, and patient's families, when deemed appropriate (AAFP, n.d. b).

A Patient-Centered Medical-Dental Home (PCM-DH) is an enhanced and evolving version of the Patient-Centered Medical Home. Oral health is being integrated into the PCMH model to address disease prevention and chronic disease treatment (Smiley, 2013). The aims of integrating these two disciplines are; increase communication and collaboration among dental and medical providers, improve quality, patient satisfaction, and health outcomes, and reduce health care costs (Hilton, 2014).

Traditionally, the delivery of medical and dental services has been divided into separate entities. Organizational silos were created in the United States health care system by dividing care into oral and systemic health care (Powell \& Din, 2008). The division of medical and dental is demonstrated through system structures such as insurance and electronic health records (EHR), causing a disconnect in payment systems. Medical insurance was designed to cover unforeseen and prodigious expenses of medical treatment modalities, while the purpose of dental insurance was to finance predictable 
restorative and preventative care with a lower-cost (Simon, 2016). Dental insurance was also perceived as a benefit, while protection from substantial medical costs was deemed a necessity (Simon, 2016). Additionally, EHRs are not integrated between dental and medical providers, which presents a barrier to the exchange of patient information, a key variable in implementing a patient-centered medical-dental home (Powell \& Din, 2008).

In 2003, The World Oral Health Report stated that "the interrelationship between oral and general health is proven by evidence" (World Health Organization, 2003). Poor oral health is associated with premature births in women with periodontal disease as well as low birth weight infants, Type II diabetes, heart disease and a greater incidence of stroke (as cited in Office of Disease Prevention and Health Promotion, n.d.). Disability is also a possible consequence of poor oral health due to complications from cardiovascular diseases. In the absence of good oral health, an individual can lose vital functions afforded by having an intact, healthy dentition such as adequate mastication and enunciation (as cited in Office of Disease Prevention and Health Promotion, n.d.). This interconnection between oral and systemic health establishes the need for integrated health care as the U.S. strives for more effective and ultimately cost-sparing models of delivery.

Integration between medical and dental service areas range from facilitated referrals to full integration, where the professionals are co-located, share infrastructure and utilize the same electronic health records (Damiano, Reynolds, McKernan, Mani, \& Kuthy, 2015). In the United States, full integration in practice is rare, although systems such as the Veterans Administration (VA) and Indian Health Services (IHS) typically provide services at a centralized location. 
The current research is a case study designed to describe the development and implementation of the Terry Reilly Health Services (TRHS) Latah Medical-DentalBehavioral Health integrated clinic in Boise, Idaho. In addition, the study will utilize a SWOT analysis to capture the perceived strengths, weaknesses, opportunities and threats of the model. Since few PCM-DH delivery systems are in place, the study presents the opportunity to share TRHS' story and potentially serve as a model for future implementation in Idaho and beyond. 


\section{BACKGROUND}

\section{PCM-DH}

According to the Agency for Healthcare Research and Quality (AHRQ), (n.d.), the PCMH model was designed with a commitment towards improvement in American health care delivery. AHRQ concluded that an integrated model could be accomplished by revamping the current organization and delivery system of primary care. For the purpose of this paper, the American Academy of Family Physician's (AAFP) definition for primary care is used. AAFP states that "primary care is that care provided by physicians specifically trained for and skilled in comprehensive first contact and continuing care for persons with any undiagnosed sign, symptom, or health concern not limited by problem origin, organ system or diagnosis" (AAFP, n.d. a). The PCMH is composed of five components: comprehensive care, coordinated care, accessible services and quality of delivery (AHRQ, n.d.).

The PCM-DH, a concept derived from the PCMH model, also encompasses these characteristics. The inclusion of dental care into the PCMH model allows for the integration of these two disciplines and allows for the focus to be on the patient as a whole, versus a single system or organ (Health Resources and Service Administration (HRSA), 2008). This unification enables increased communication between the disciplines, facilitates collaboration, improves the quality of care being delivered and reduces costs for both health care teams (Hilton, 2014). 


\section{Oral Health Integration}

There is broad consensus that integration of oral health care into the primary health care system would allow for more holistic and comprehensive patient-centered care (Riter, Maier \& Grossman, 2008; Thema \& Singh, 2013; Monajem, 2006; Tomar \& Cohen, 2010; as cited in Kandelman, Arpin, Baez, Baehni, \& Petersen, 2012). While the need for oral health integration into the primary care system is well established, few health care organizations or practices have implemented this model (Monajem, 2006). The following literature review discusses the attributes of an ideal oral health care system and integration of oral health into the primary care system.

\section{$\underline{\text { Ideal Oral Health Care System }}$}

Fourteen attributes of an ideal oral health system have been identified in policy statements and position papers from the World Health Organization, Institute of Medicine, American Public Health Association, Healthy People 2010 Objectives for the Nation, and the American Association of Public Health Dentistry (Tomar \& Cohen, 2010). An ideal oral health system would be comprised of a fully integrated health care system focused on health promotion and disease prevention, assessment of oral health status and needs, continuous quality improvement and assurance, and empowerment of communities and individuals to promote a healthy environment. Characteristics also include the provision of evidence-based, effective, cost-effective, sustainable, equitable, universal, comprehensive, ethical, and culturally competent care (Tomar \& Cohen, 2010). Medical-dental integration would include many of these attributes. 


\section{$\underline{\text { Integration into Primary Care Systems }}$}

Young children, particularly individuals with lower socio-economic status, tend to visit primary health care providers more frequently than dental professionals. This allows for opportunities for primary health care providers to detect early stages of oral disease, educate the patient on oral hygiene and refer the patient to the appropriate dental professional before extensive treatment is needed (Tomar \& Cohen, 2010; Kandelman et al., 2012; Thema \& Singh, 2013). Integration, primarily in pediatric care settings, range from incorporating preventative oral health services into primary care (Riter et al., 2008) to a medical and health home model (Damiano et al., 2015). When the two systems work together, essential preventative dental care can be provided in a timely manner in one clinical setting.

$\underline{\text { Potential Impact of Oral Health Integration }}$

Integration of oral health into the primary care system has the potential to have significant impact at the patient, provider and system level (Grantmakers in Health, 2012). The ability to perform "in house" referrals in an integrated health center can improve outcomes, reduce care costs and increase oral health access.

Improve Health Outcomes and Reduce Health Care Costs. When medical and dental providers work collaboratively, there is a potential for improved effectiveness for holistic care and heightened efficiency regarding disease prevention, and improved management of chronic illnesses (as cited in Damiano et al., 2015; Pew Center on the States, 2012). Examples include having medical and dental health providers engaged in the prevention of dental caries in young children. Another potential benefit of integration is cost savings. A 2013 national study estimated that medical screenings conducted in 
dental offices for diabetes, hypertension and hypercholesterolemia could save the United States healthcare system between $\$ 42.4$ million and \$102.6 million a year, depending on patient compliance with acting on the referral (Nasseh, Greenberg, Vujicic, \& Glick, 2014). Conversely, Cigna found that when individuals received appropriate periodontal care, they had an average medical cost savings of $\$ 1,292$ with diabetes, $\$ 2,183$ with heart disease and $\$ 2,831$ for those that had suffered a stroke (Hall, 2014). These findings support the benefits of the model both from a patient and societal perspective.

Improve Physical Access and Patient-Specific Barriers. Oral health service access is a barrier for underserved and vulnerable populations (American Dental Association, n.d.). Integration would expand the entry points into the dental care system (Institute of Medicine (IOM), 2011; Institute of Medicine (IOM) and National Research Council (NRC), 2011). By enabling early access through a medical-dental-behavioral health setting, where all disciplines are under the same roof and coordinating care, individuals can get the care they need sooner. Also, diseases can potentially be prevented, health promoting behaviors can be reinforced and patient satisfaction with providers and outcomes can be increased.

Patient-specific barriers to accessing dental care could also be addressed with the use of interdisciplinary techniques (as cited in Munger, 2012). By integrating the knowledge, skills and experience of medical, dental, and behavioral health disciplines, a comprehensive treatment plan, with maximized results can be developed (Rogers et al., 2000). For example, dental anxiety or apprehension could be addressed in real-time thus increasing patient comfort and trust in the provider. The more patients trust their health 
care providers, the more likely they will believe in the importance of physical and oral health and engage in proactive health behaviors.

Models of Oral Health Integration

The National Maternal and Child Oral Health Policy Center (NMCOHP) (2011) have theorized five potential models for medical-dental integration. There are a range of approaches and strategies because a "one size fits all” model for medical-dental integration does not exist. Not all states, communities, or practices have the resources, space, or funding to have a fully integrated system in place. These five models give the adaptor the option to implement a strategy that fits best within their setting (National Maternal and Child Oral Health Policy Center, 2011).

The five models, with examples of each are provided below.

- A facilitated, formalized referral system between providers that allows for better tracking and follow-up with patients (National Maternal and Child Oral Health Policy Center, 2011; Rhode Island Health Center Association (RIHCA), 2011).

- Health centers with formal contracts with dental providers for the inclusion of dental services are an example of this model (RIHCA, 2011).

- A virtual integration model is based on having a common health record system that can be seen by both dental and medical professionals.

○ The Veteran's Administration uses this model (National Maternal and Child Oral Health Policy Center, 2011; RIHCA, 2011). 
- A shared financing model is based on a payer model in place where dental and medical professionals share the same financial risks and opportunities for a shared group of patients.

○ United Healthcare's pilot AmeriChoice Program in New Jersey, where primary care medical providers are being reimbursed for oral health screenings, preventative counseling, and fluoride varnish services and completing a timely pediatric dental referral, is an example of this model.

- A co-location model where both medical and dental providers work within the same building but operate separately and do not coordinate care (National Maternal and Child Oral Health Policy Center, 2011; RIHCA, 2011).

○ Federally Qualified Health Centers (FQHCs) that provide both dental and medical services within the same building are an example of this model (National Maternal and Child Oral Health Policy Center, 2011; RIHCA, 2011).

- The model with the highest level of integration entails a dentist being a part of an inter-professional group of providers that practice at a single location, collaboratively, in order to provide comprehensive care to their patients (National Maternal and Child Oral Health Policy Center, 2011; RIHCA, 2011).

- Although full integration in practice is rare, TRHS Latah Clinic is an example of this model. 
Table 1 provides a summary of the five potential models for medical-dental

integration.

Table 1

The Five Potential Models for Medical-Dental Integration

\begin{tabular}{lll}
\hline Model & Characteristics & Example \\
\hline Referral System & $\begin{array}{l}\text { Facilitated, formalized referral system } \\
\text { between providers }\end{array}$ & $\begin{array}{l}\text { Health Centers with } \\
\text { formal contracts with } \\
\text { dental provider for the } \\
\text { inclusion of dental } \\
\text { services }\end{array}$ \\
Virtual Integration & $\begin{array}{l}\text { Common health record system that can } \\
\text { be seen by both medical and dental } \\
\text { providers }\end{array}$ & Veteran's Administration \\
Shared Financing & $\begin{array}{l}\text { Payer model when dental and medical } \\
\text { professionals share the same financials } \\
\text { risk and opportunities or a shared group } \\
\text { of patients }\end{array}$ & $\begin{array}{l}\text { United Healthcare's pilot } \\
\text { AmeriChoice Program in }\end{array}$ \\
& $\begin{array}{l}\text { Medical and dental providers work } \\
\text { within the same building BUT operate } \\
\text { Separately and do NOT coordinate care }\end{array}$ & $\begin{array}{l}\text { FQHCs that provide both } \\
\text { dental and medical } \\
\text { services within the same } \\
\text { building }\end{array}$ \\
& $\begin{array}{l}\text { Dentist being a part of an inter- } \\
\text { professional group of providers that } \\
\text { practice at a single location, } \\
\text { collaboratively, in order to provide } \\
\text { comprehensive care to their patients }\end{array}$ & TRHS Latah Clinic \\
\hline \multirow{2}{*}{ Full-Integration } & & \\
\hline
\end{tabular}

Levels of Collaboration/Integration

Within the most integrated model, six levels of collaboration have been identified by the Substance Abuse and Mental Health Services Administration (SAMHSA)-Health Resources and Services Administration's (HRSA) Center for Integrated Health Solutions (CIHS) (2013). These six levels have been divided into three main categories of integrated care: coordinated, co-located, and integrated, with two sub-levels within each category. 
Coordinated care is designated as level one and two on the integration scale.

Level one has minimal collaboration between providers. Providers deliver care in separate facilities, with separate systems and rarely communicate about cases (SAMHSA-HRSA CIHS, 2013). Level two consists of basic collaboration at a distance. Providers deliver care at separate facilities, with separate systems, but view providers of other disciplines as resources and periodically communicate about shared patients (SAMHSA-HRSA CIHS, 2013).

Co-located care is designated as level three and four on the scale. Level three has basic collaboration on site. Providers are co-located in the same facility, but may not share the same practice space, and continue to use separate systems (SAMHSA-HRSA CIHS, 2013). Level four includes close collaboration with some level of system integration. The providers share the same practice space and are introducing integrated care through some shared systems, i.e., the primary care receptionist schedules all appointments and the other disciplines have access to and can enter notes into a patient's health record (SAMHSA-HRSA CIHS, 2013).

Integrated care is designated as levels five and six on the scale. Level five demonstrates close collaboration that is approaching an integrated practice. There is a high level of collaboration and integration between providers, allowing them to function as a team, but some issues, i.e., availability of an integrated medical record, may not be in place (SAMHSA-HRSA CIHS, 2013). Level six, the highest level of integration, consists of full collaboration in a transformed/merged practice. Both providers and patients view the operation as a single health system designed to provide comprehensive treatment to every patient (SAMHSA-HRSA CIHS, 2013). 
Figure 1 is a graphic produced by the Center for Integrated Health Solutions used to describe the levels of collaboration

(SAMHSA-HRSA CIHS, 2013).

\begin{tabular}{|c|c|c|c|c|c|}
\hline \multicolumn{2}{|c|}{$\begin{array}{c}\text { COORDINATED } \\
\text { KEY ELEMENT: COMMUNICATION }\end{array}$} & \multicolumn{2}{|c|}{$\begin{array}{c}\text { CO LOCATED } \\
\text { KEV EI EMENT. PHYCICAI PROYIMITY }\end{array}$} & \multicolumn{2}{|c|}{ INTEGRATED } \\
\hline $\begin{array}{l}\text { LEVEL } 1 \\
\text { Minimal Collaboration }\end{array}$ & $\begin{array}{l}\text { LEVEL } 2 \\
\text { Basic Collaboration } \\
\text { at a Distance }\end{array}$ & $\begin{array}{l}\text { LEVEL } 3 \\
\text { Basic Collaboration } \\
\text { Onsite }\end{array}$ & $\begin{array}{c}\text { LEVEL } 4 \\
\text { Close Collaboration } \\
\text { Onsite with Some } \\
\text { System Integration }\end{array}$ & $\begin{array}{c}\text { LEVEL } 5 \\
\text { Close Collaboration } \\
\text { Approaching } \\
\text { an Integrated Practice }\end{array}$ & $\begin{array}{l}\text { LEVEL } 6 \\
\text { Full Collaboration in } \\
\text { a Transformed/ Merged } \\
\text { Integrated Practice }\end{array}$ \\
\hline \multicolumn{6}{|c|}{ Behavioral health, primary care and other healthcare providers work: } \\
\hline $\begin{array}{l}\text { In separate facilities, } \\
\text { where they: }\end{array}$ & $\begin{array}{l}\text { In separate facilities, } \\
\text { where they: }\end{array}$ & $\begin{array}{l}\text { In same facility not } \\
\text { necessarily same offices, } \\
\text { where they: }\end{array}$ & $\begin{array}{l}\text { In same space within the } \\
\text { same facility, where they: }\end{array}$ & $\begin{array}{l}\text { In same space within } \\
\text { the same facility (some } \\
\text { shared space), where } \\
\text { they: }\end{array}$ & $\begin{array}{l}\text { In same space within the } \\
\text { same facility, sharing all } \\
\text { practice space, where } \\
\text { they: }\end{array}$ \\
\hline $\begin{array}{l}\text { Have separate systems } \\
\text { Communicate about cases } \\
\text { only rarely and under } \\
\text { compelling circumstances } \\
\text { Communicate, driven by } \\
\text { provider need } \\
\text { May never meet in person } \\
\text { Have limited understand- } \\
\text { ing of each other's roles }\end{array}$ & $\begin{array}{l}\text { Have separate systems } \\
\text { Communicate periodically } \\
\text { about shared patients } \\
\text { Communicate, driven by } \\
\text { specific patient issues } \\
\text { May meet as part of larger } \\
\text { community } \\
\text { Appreciate each other's } \\
\text { roles as resources }\end{array}$ & $\begin{array}{l}\text { Have separate systems } \\
\text { Communicate regularly } \\
\text { about shared patients, by } \\
\text { phone or e-mail } \\
\text { Collaborate, driven by } \\
\text { need for each other's } \\
\text { services and more reliable } \\
\text { referral } \\
\text { Meet occasionally to } \\
\text { discuss cases due to close } \\
\text { proximity } \\
\text { Feel part of a larger yet } \\
\text { non-formal team }\end{array}$ & $\begin{array}{l}\text { Share some systems, like } \\
\text { scheduling or medical } \\
\text { records } \\
\text { Communicate in person } \\
\text { as needed } \\
\text { Collaborate, driven by } \\
\text { need for consultation and } \\
\text { coordinated plans for } \\
\text { difficult patients } \\
\text { Have regular face-to-face } \\
\text { interactions about some } \\
\text { patients } \\
\text { Have a basic } \\
\text { understanding of roles } \\
\text { and culture }\end{array}$ & $\begin{array}{l}\text { Actively seek system } \\
\text { solutions together or } \\
\text { develop work-a-rounds } \\
\text { Communicate frequently } \\
\text { in person } \\
\text { Collaborate, driven by } \\
\text { desire to be a member of } \\
\text { the care team } \\
\text { Have regular team } \\
\text { meetings to discuss overall } \\
\text { patient care and specific } \\
\text { patient issues } \\
\text { Have an in-depth un- } \\
\text { derstanding of roles and } \\
\text { culture }\end{array}$ & $\begin{array}{l}\text { Have resolved most or all } \\
\text { system issues, functioning } \\
\text { as one integrated system } \\
\text { Communicate consistently } \\
\text { at the system, team and } \\
\text { individual levels } \\
\text { Collaborate, driven by } \\
\text { shared concept of team } \\
\text { care } \\
\text { Have formal and informal } \\
\text { meetings to support } \\
\text { integrated model of care } \\
\text { Have roles and cultures } \\
\text { that blur or blend }\end{array}$ \\
\hline
\end{tabular}

Figure 1. Six Levels of Collaboration/Integration 
Characteristics of a Fully-Integrated System. As part of the HRSA Oral Health Disparities Collaborative, characteristics of full medical-dental integration were identified through the work of four pilot centers (National Network for Oral Health Access (NNOHA), 2008). These characteristics, based on a Care Model framework, have been organized into six categories and are provided below:

- Clinical Information Systems

○ Characteristics include: an integrated electronic health record and scheduling system, and closing the information loop on referrals to ensure that patients are being seen (NNOHA, 2008).

- Decision Support

- Characteristics include: a greater understanding of dental practices among the medical staff, the importance of oral health for pediatric and pregnant patients, and a referral system in place from medical to dental, ensuring access to care (NNOHA, 2008).

- Delivery System Design

○ Characteristics include: integrated care team pods, shared support staff, dental staff presence, and oral health integration into all medical appointments via screenings and education (NNOHA, 2008).

- Self-Management category

○ Characteristics include: co-location of patient education materials and an integrated goal sheet (NNOHA, 2008).

- Organization of Health Care 
○ Characteristics include: co-located disciplines, integrated staff meetings, systems of care coordinated to address all disciplines at each visit, cultural competency, and integrated case management (NNOHA, 2008).

- Community Resources

- Characteristics include: creating patient awareness that oral health is associated with overall health, insurance and reimbursement structures adjusted to include oral health and dental screenings into WIC, Head Start and Early Head Start appointment (NNOHA, 2008).

Each of the listed structures, systems and characteristics are indicative of a fully integrated system. The more aspects that a model possesses, the higher the level of integration.

As evidenced by this review of oral health integration, there are a variety of strategies that could be used to meld the practices of medicine and dentistry. These varied approaches highlight the need for careful planning and strong leadership in integration efforts.

\section{Medical and Dental Professional's Perceptions of Integration}

There are many perceptions about integration of oral health into the medical care system. Some medical practitioners believe "problems with swallowing are my department while problems with chewing are the dentist's department" (Anderrson, Furhoff, Nordenram, \& Wårdh, 2007). Integrated oral health's future will rely on medical and dental professionals coming together to promote prevention, address access to care 
issues and to foster effective communication between dental and medical homes (Boulter, 2011).

According to a study conducted by Rabiei, Mohebbi, Patja, \& Virtanen, (2012) there is a lack of knowledge in oral health care among primary care physicians, but they have a generally positive attitude and willingness to take part in basic dental prevention measures. The Advanced General Dentistry program directors firmly supported the involvement of physicians in routine dental assessments, looking for early signs of dental complications, especially for pediatric patients and educating patients on preventative dental measures (Raybould, Wrightson, Massey, Smith, \& Skelton, 2009).

\section{Barriers to Integration}

Barriers exist from both a system level and provider perspective. System-level barriers identified by the National Network for Oral Health Access were; lack of capacity, absence of integrated electronic medical and dental health records, training, and policies and protocols, competing needs, and reimbursement issues (Hilton, 2014).

Commonly recognized barriers are; that the dentist's professional domain is the dentition and oropharynx, the sharing of information is an uncommon practice between dental and medical providers, and that professional values, beliefs, attitudes, customs and behaviors could create challenges (as cited in Bernstein et al., 2016). Research indicates that physicians identify lack of time and knowledge as major barriers to the integration of oral health care in treatment planning (Anderrson et al., 2007; Lewis, Barone, Quinonez, Boulter, \& Mouradian, 2013; and Rabiei, Mohebbi, Patja, \& Virtanen, 2012). 


\section{Terry Reilly Health Services}

TRHS, established in 1971, began as an education and literacy program for the migrant seasonal farm workers in Nampa, Idaho. The founder, Terry Reilly, noticed that many of the workers and their children had physical and systemic health problems and lacked access to healthcare. From the inception of the organization, TRHS has been dedicated to providing access to affordable, comprehensive care that improves the health and quality of life of their patients (Terry Reilly Health Services, n.d.).

TRHS is incorporated under the name of Community Health Clinics Inc. and encompasses nine medical clinics, seven dental clinics, six behavioral health locations, and one pharmacy (Terry Reilly Health Services, n.d.). TRHS has also has been designated as a Federally Qualified Health Center (FQHC). A FQHC is defined as a community-based health center that provides primary care services to an underserved area, with the help of funding from the HRSA Health Center Program (Health Resources \& Services Administration (HRSA), n.d.). To be declared a FQHC, a facility must provide care on a sliding fee scale and operate under a governing board that includes patients (HRSA, n.d.). TRHS is classified as a Community Health Center, Migrant Health Center, and Health Care for the Homeless. Per the 2015 TRHS annual report, their patients were primarily Caucasians (52\%), between the ages of 20 and 64 (73\%), and uninsured (58\%) (Terry Reilly Health Services, 2015). TRHS was also the first community health clinic in the state of Idaho to be certified as a PCMH (Terry Reilly Health Services, n.d.). 


\section{The TRHS Latah Medical-Dental-Behavioral Health Clinic}

The setting for this case study is TRHS Latah Clinic. The Latah Clinic, located in Boise, Idaho, was the first TRHS clinic outside the Nampa metropolitan area to be established. In 2015, TRHS conducted a community assessment to identify needed services in the Central Bench area. In late 2015/early 2016, the clinic was renovated with funds from a federal grant, to accommodate medical, dental and behavioral health services. The clinic was the first TRHS facility to be designed to accommodate full integration of the health care team.

As a TRHS leadership member shared, they chose this integrated approach because of how we as individuals experience the healthcare system. "I go into a building as a body... and I have all of the parts of my body connected and I'm going to get help to take care of me and it doesn't matter whether it's my feelings, my heart, or my tooth...it's my body and I'm looking for a group of people to take care of my body and who I am within that body". The TRHS Latah Clinic is wanting their "system to be able to be as seamless [as possible] so that what the patient experiences is being treated like the person that they are". 


\section{METHODS}

This study was designed to describe the development and implementation of the Terry Reilly Health Services (TRHS) Latah Medical-Dental-Behavioral Health Integrated Clinic (Latah Clinic). Data was collected in the following ways: structured interviews with a purposive sample of employees from TRHS; observations of a Latah Clinic care team meeting; an environmental scan of facility space; and an analysis of intake forms used at the Latah Clinic. The Boise State University Institutional Review Board approved the methods and materials utilized in this study (approval number 193-SB17-053).

\section{Key Informant Recruitment}

Employees of TRHS (key informants) were recruited for participation in April 2017. Key informants included the Chief Executive Officer (CEO), Chief Operating Officer (COO), Director of Quality Improvement, Director of Clinical Operations, Medical Director, Nursing Director and Dental Director.

After introduction by the $\mathrm{COO}$, the principal investigator (PI) contacted perspective key informants by email to solicit their participation in a structured conversational interview. Appendix A includes the recruitment message that was sent via e-mail to the key informants.

One informant did not respond. Three requested to have the interview conducted via e-mail, but only two were completed. Three participants requested an in-person 
interview. Those agreeing to participate were asked to review and sign an informed consent, see Appendix B.

\section{Key Informant Tools}

Two structured interview scripts were developed by the PI. Prior to use, each tool was pilot tested to ensure clarity and sensitivity. One script was tailored for informants from the Latah Clinic; Director of Clinical Operations, Medical Director, Nursing Director and Dental Director and the other was designed for members of the leadership team at TRHS; CEO, COO, and Director of Quality Improvement.

\section{$\underline{\text { Latah Clinic Key Informant Tool }}$}

The structured interview questions, included in Appendix C, were developed using a SWOT framework. The script was comprised of various components: background information, perceived strengths and weaknesses regarding the integrated model, and recommendations. Background information questions inquired about work history with TRHS, previous employment, and how they would describe the operations at the Latah Clinic.

The second component focused on the strengths and weaknesses of practice processes and patient outcomes, as well as perceived opportunities and threats to the model.

The final component asked informants to provide recommendations on what to keep the same or change if someone were to replicate the Latah Clinic operations. Informants were also provided with an opportunity to share additional comments. 


\section{$\underline{\text { TRHS Leadership Key Informant Tool }}$}

The structured interview questions asked leadership team informants to describe the history and operations at TRHS Latah Clinic, included in Appendix D. The script was comprised of three components: background of TRHS, level of integration at the Latah Clinic and the future of the Latah Clinic. The interview began with questions inquiring about the history of TRHS and the Latah Clinic.

The second component consisted of questions structured around the five potential models for medical-dental integration identified by the NMCOHP (2011). For example, participants were asked, "Is there a facilitated, formalized referral system between providers that would allow for better tracking and follow-up with patients in place". Based on the descriptions provided, informants were asked to describe the level of integration at the Latah Clinic, identify if it was different than other TRHS facilities, and describe what opportunities allowed for the level of integration.

Finally, informants were asked about the future of the Latah Clinic and how the model may impact other TRHS clinics. Informants could also share additional comments.

\section{Latah Clinic Care Team Meeting Observations}

Two investigators attended the Latah Clinic Care Team Meeting on May 2, 2017, with the permission of the COO. The purpose of this observation was to note evidence of integration during staff meetings. During this meeting, the following aspects were observed; structure/agenda of the meeting, meeting location, seating arrangements and roles and level of engagement of participants. See Appendix E for observation checklist. 


\section{Environmental Scan}

After obtaining permission from the COO, the PI visited the Latah Clinic on two separate occasions to conduct the environmental scan. The purpose of this scan was to document evidence of integration within the building design and use of space. During the environmental scan, the following factors were documented; general structure/layout of the clinic, allocation of space and equipment for each department and balance of space between departments. See Appendix G for scan checklist.

The first visit to the clinic was a tour, guided by the COO, designed to provide the PI with a general understanding of the structure/layout of the clinic. The second visit was used to take photographs of the clinic and document the visual layout of the clinic.

\section{Intake Forms}

During the second visit to the Latah Clinic, the PI was provided access to the dental and behavioral health intake forms and the patient registration form. The medical intake form was unavailable due to the electronic nature of the form and patient privacy concerns. The purpose of this analysis was to note evidence of integration found within the intake forms provided to patients. A checklist developed by the PI guided analysis of the forms. Factors included: utilization of a single intake form, equivalent questions for each department and identification of whether the forms addressed the patient's primary concern. See Appendix H for intake form checklist.

\section{Procedures}

At the beginning of the study period, the PI obtained permission from the $\mathrm{COO}$ in order to; attend and observe a Latah Clinic group meeting; conduct an environmental 
scan of the Latah Clinic; conduct conversational interviews with key informants; and analyze the initial intake forms.

The COO also provided the PI with e-mail contact information for key

informants. Recruitment activities were conducted and informants agreeing to participate were asked to read and sign informed consent forms.

Three interviews were completed via e-mail and three were conducted face-toface between April 19 and April 24. Each interview was approximately 15 minutes in length. The PI transcribed the interviews for analysis.

An individual with 36 years of dental experience was recruited to join the PI as a research assistant. The assistant attended the Latah Clinic team meeting and also assisted with analysis of interviews.

On May 2, 2017, the PI and research assistant attended the Latah Care Team Meeting. Observations were recorded using a developed checklist. The PI visited the Latah Clinic again to take photographs and obtain copies of the intake forms. Checklists were used to guide the environmental scan and review of forms.

All notes from meeting, the environmental scan, interviews and analysis of intake forms were maintained in a secure Boise State University shared drive accessible to only the PI and Co-Investigator.

\section{Analysis Plan}

\section{$\underline{\text { Latah Clinic Key Informant Tool }}$}

Interviews were transcribed verbatim by the PI and then analyzed by the PI and research assistant. Similarities and differences were noted between the three interviews and a SWOT diagram was utilized to aggregate identified perceived strengths, 
weaknesses, opportunities and threats of the integrated model from all interviews. Recurring themes were also identified.

TRHS Leadership Key Informant Tool

Each interview was transcribed verbatim and analyzed by the PI and research assistant. Similarities and differences were noted between the two interviews and responses were used to identify the integration models being utilized at the Latah Clinic. $\underline{\text { Latah Clinic Care Team Meeting Analysis }}$

The PI and research assistant utilized a checklist developed by the PI to guide observations during the meeting. Notes from the meeting were compiled and analyzed. $\underline{\text { Environmental Scan Analysis }}$

The PI documented observations, utilizing the developed checklist, and used photographs of the Latah Clinic to provide a visual representation of the clinic setting. $\underline{\text { Intake Forms Analysis }}$

Using the developed checklist, the PI documented similarities, differences and evidence of integration among the forms. 


\section{RESULTS}

\section{Latah Clinic Key Informants}

Three interviews were conducted, two via e-mail and one face-to-face, utilizing the Latah Clinic Key Informant tool. The interview was comprised of three components: background information, perceived strengths, weaknesses, opportunities and threats regarding the integrated model, and future recommendations.

\section{$\underline{\text { Background Information }}$}

The informant's employment history with TRHS ranged from $2 \frac{1}{2}$ to $71 / 2$ years and they stated their role at the Latah Clinic was similar, if not the same, as previous job responsibilities. When asked to describe the operation of the clinic, all respondents stated that it is an efficient, collaborative, and an integrated clinic.

\section{$\underline{\text { SWOT Analysis }}$}

Informants provided what they perceived as strengths and weaknesses of practice processes and patient outcomes, as well as opportunities and threats to the integrated model.

Strengths of the model were that it is collaborative, efficient, comprehensive, and has demonstrated evidence of enhancing outcomes. One informant stated, "So it's just ease of consultation is just amazing when you're...sitting...just a few feet away from all these other disciplines. That just makes it like a one-stop shop for the patients. For the patient experience, I think [it] is very, rewarding because they're getting two people's expert...opinions. Not just a family doctor's opinions, but a psych provider or a dentist". 
Weaknesses of implementation of the model included; space constraints, the need for added flexibility and more time to complete the patient intake process, inefficient scheduling coordination and inadequate staffing ratios. For example, one informant said, “Just one MA (medical assistant) per provider is just not enough in a place where a lot of care is being delivered."

Perceived opportunities were the ability to expand, enhanced ability to improve health outcomes, and the potential to increase the overall health of the country. Threats to the continued success of the Latah Clinic included lack of acceptance by other providers, funding, and anti-immigration attitudes within the United States generating fear and concern for patients. See Table 1 for additional details gathered through the SWOT.

Table 2

\section{SWOT Analysis from Latah Clinic Key Informant Interviews}

STRENGTHS WEAKNESSES

Team interactions/collaborative spirit Limited space

Patient flow/handoffs/easy to get a consult Inability to monitor routine registries for basic preventative health measures

Quality outcomes meet or exceed expected values/better outcomes/delivering an

Requires more flexibility in operations outstanding product in a small building

An example for the corporation

None (2)

Patients can get appointments with different disciplines

Multiple forms for the patient to fill out - Time consuming

Patients are being treated as a whole/comprehensively

Saving time, energy and resources/more efficient

Complex data entry for the front desk

- Time consuming

Scheduling can be challenging

- No shows

- Tardiness

Patients are getting better faster

Inadequate staffing ratio

- More medical attention in a concentrated fashion 
OPPORTUNITIES

None at this time

New services/expanding

Improved outcomes

Integrated facilities have the potential to make our country healthier

\section{THREATS}

None I am aware of

Lack of acceptance or perception of competition from other providers

Lack of funding/payment sources

- Cut funding for FQHCs

- Cut Medicaid spending

Anti-immigration prejudices

- Latino population intimidated by perceived prejudices

\section{$\underline{\text { Recommendations from Key Informants }}$}

Informants also provided recommendations for improvements or continuation of existing practices in replicating the Latah Clinic operations. The informants felt it was important to include all three disciplines, select clinicians who share a common vision for integration of information and referrals in a shared location. One informant felt the model would be more successful in smaller clinics. Others noted the importance of carefully considering space/layout or implementing "quiet spaces in" the facility. For example, one informant stated, "The physical layout doesn't have to be exactly the way we have it because it does get loud".

A shortage of available medical assistants on certain days was cited as a barrier to efficient workflow. Without adequate staffing, appointments are being lengthened, lab work is taking longer to complete and patients are not being provided efficient care. Other recommended changes were to increase behavioral health services. The addition of another full-time professional would allow for more patients to be seen within a given time period. Additional office space would increase ability and capacity for more patient/provider consultations. 


\section{TRHS Leadership Key Informants}

Two face-to-face interviews were conducted, utilizing the TRHS Leadership Key Informant tool. The interview was comprised of three components: background on TRHS, level of integration at the Latah Clinic and the future of the Latah Clinic. Background information on TRHS has been reported on pages 16-17.

\section{$\underline{\text { Integration Level }}$}

Informants were asked to describe the level of integration at the Latah Clinic, identify if it was different than other TRHS facilities, and describe the circumstances that allowed for the level of integration.

Participants were guided to compare clinic operations to the five potential models for medical-dental integration identified by the NMCOHPC (2011). The informants agreed that the Latah Clinic has a formalized referral system, a common EHR system, and is fully integrated. Conversely, the Latah Clinic lacks a payer model for sharing of financial risks and opportunities and does not fully represent the co-location model where the providers are within the same building but operate separately and do not coordinate care. See Table 4 and the key for the questions the interviewees were asked and their responses.

Table 3

Integration Models Utilized at the Latah Clinic

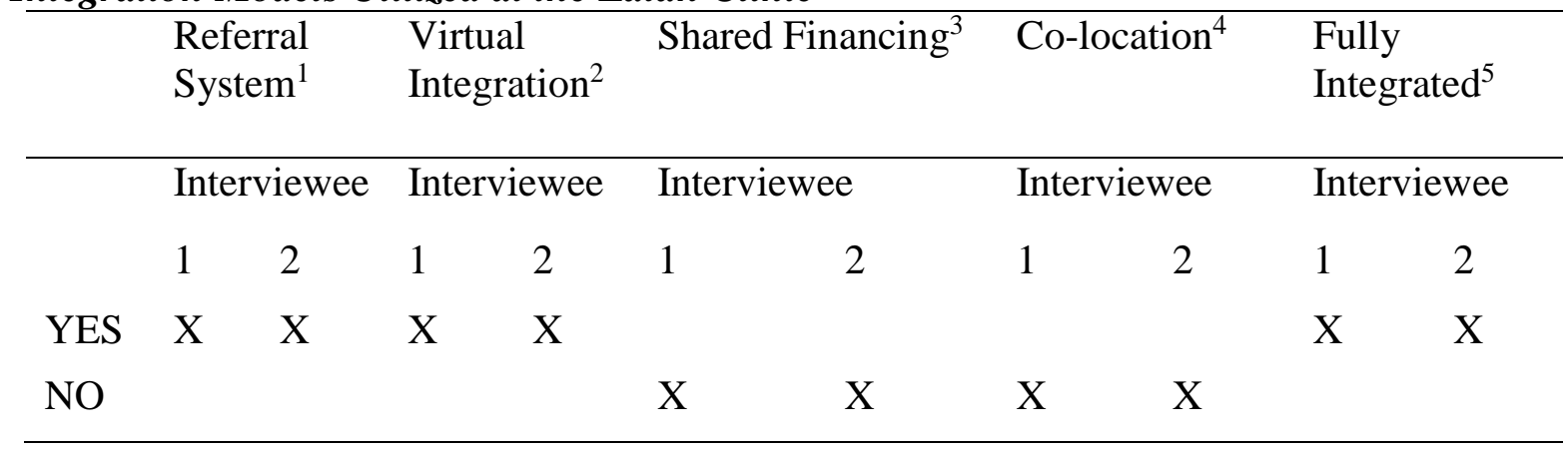


Note. ${ }^{1}$ Referral System - Is there a facilitated, formalized referral system between providers that would allow for better tracking and follow-up with patients in place?

${ }^{2}$ Virtual Integration - Is there a common electronic health record system that can be seen by both dental and medical professionals in place?

${ }^{3}$ Shared Financing - Is there a payer model in place where dental and medical professionals share the same financial risks and opportunities for a shared group of patients?

${ }^{4}$ Co-located: Same building - operate separately/not coordinate care - Do dental and medical providers work within the same building but operate separately and not coordinate care?

${ }^{5}$ Fully Integrated: Inter-professional group of providers that practice at a single location, collaboratively, in order to provide comprehensive care - Is the dentist a part of an interprofessional group of providers that practice at a single location, collaboratively, in order to provide comprehensive care to their patients?

According to the informants, it is unlikely that the shared financial risks/opportunities model would be viable in Idaho. As one informant stated, “...so long as the third-party carriers stay within their box of their domain, we're not going to probably have integrated contracts...right now they're really carved out by discipline within Idaho".

The Latah Clinic partially represents the co-location model described by the NMCOHP. The clinic does have providers working within the same building, but they also operate together and coordinate care, which are not attributes of the co-location model.

When informants were asked how they would describe the level of integration at the Latah Clinic, one informant voiced that the Latah Clinic was at a level 5 or 6 on the integration scale developed by SAMSHA (2014) and both believed that processes were going well. These informants also agreed that the level of integration at the Latah Clinic was higher than the other TRHS clinics and that, due to its success, the Latah model would be used to guide future implementation efforts. Funding and infrastructure were 
the main opportunities that made the integration at the Latah Clinic possible. "Without those two pieces...I don't think there's a way we could've done it" said one informant. Perceptions of Latah Clinic Future

Informant consensus indicated that the participants feel the Latah Clinic will continue to improve over time and will serve as a model for future clinics. One informant voiced the concern that they may quickly outgrow the facility, but they will continue to expand the clinic until they have reached capacity.

\section{Latah Care Team Meeting Observations}

Observation of the Latah Clinic Care Team meeting occurred on May 2, 2017 from 12:00pm to $1: 00 \mathrm{pm}$ in the clinic waiting room. The clinic was closed to patients for the staff meeting to take place. Medical, dental and behavioral health staff, a facilitator (the clinic manager), a note taker, and three administrators were in attendance at the Latah Clinic Care Team meeting. Every seat in the waiting room was occupied and participants faced the reception desk. It was not apparent which department staff members represented, i.e., staff from each department were dispersed throughout the room.

A detailed agenda was provided by the facilitator, see Appendix F. The agenda identified topics and the discussion leaders. The meeting had multiple foci, that were both patient and process based. The topics for this meeting included; welcome, corporate updates, patient-centered access, team-based care, population health management, care management and support, care coordination, performance measurement/quality improvement and registry management. 
The facilitator led the meeting, making sure all topics were addressed and that participants stayed focused. Employees provided additional information and asked questions as needed. Everyone participated. The meeting concluded by reading "KUDOS" for employees from all disciplines, ranging from welcoming new staff members to appreciation for support.

A subsequent conversation occurred with the Latah Clinic dentist, the PI and research assistant, inquiring into her perceptions of referral flow between providers. The dentist voiced her admiration of the level of integration at the clinic and how the disciplines work together to deliver a comprehensive model of care. She noted a lack of knowledge concerning "when to refer to dental" among medical providers, which hinders the model. Better coordination between medical and dental providers could improve outcomes by medical staff briefly examining a patient's oral health with a tongue depressor, looking for inflammation, broken or missing teeth, halitosis or difficulty chewing. If a medical provider does not know when to refer, then the disease will continue to manifest and jeopardize both medical and dental outcomes. Another comment made by the dentist was that the success of integration at the Latah Clinic could be contributed to the fact that all providers were hired during the inception of the Latah integrated clinic. Per the conversation, TRHS clinics that are now switching to a more integrated model have experienced challenges with collaboration between providers. This may be due to providers entering into the delivery model at different times.

\section{Environmental Scan}

TRHS' Latah Clinic is a 3,753 square-foot facility located on the Central Bench. The clinic was recently remodeled and is comprised of two behavioral health consultation 
rooms, one medical lab, nine medical examination rooms, one medical procedure room, one dental sanitation room, two dental examination/dental hygiene operatories, one dental procedure room, and a provider "pod". Medical and behavioral health operate Monday through Friday, 8:00 am - 5:00pm, while the dental schedule is Tuesday, Wednesday and Thursday from 7:30 am - 12:30pm and 1:00pm - 6:00pm. Figure 2 shows the outside of the Latah Clinic.

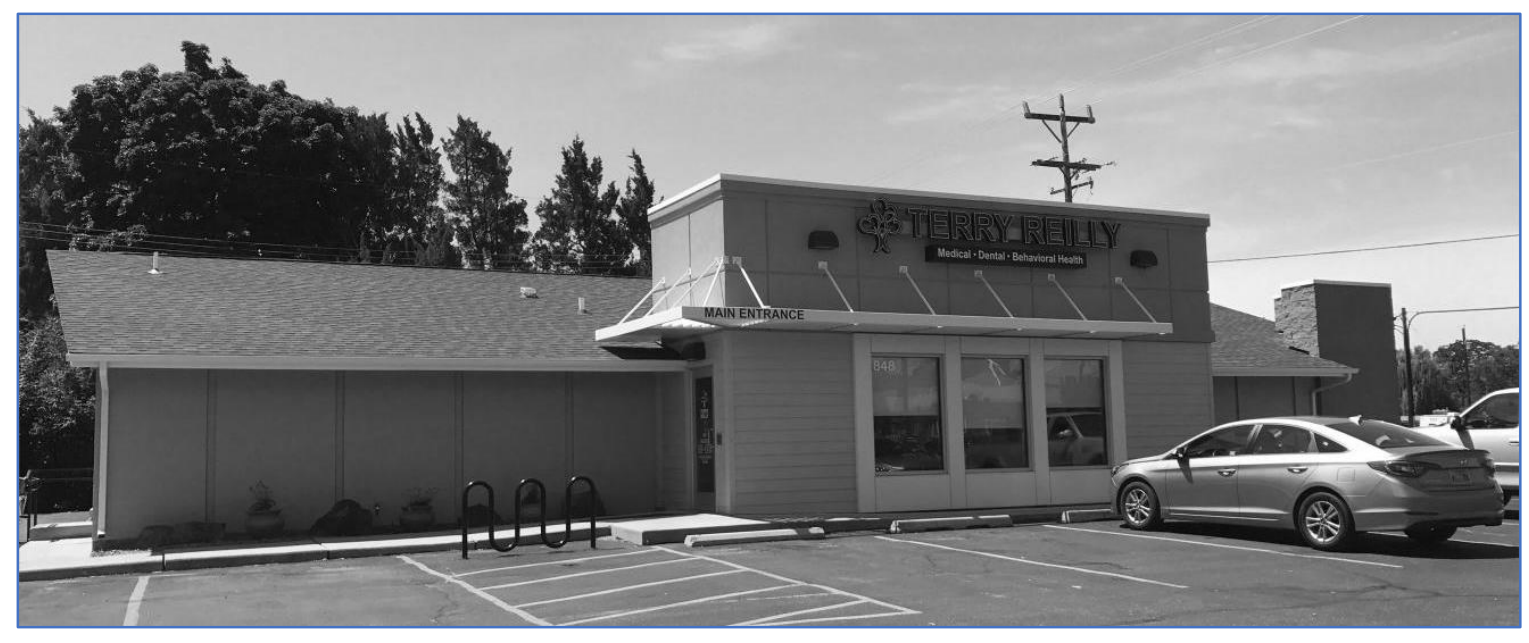

\section{Figure 2. Outside of the Latah Clinic}

A well-lit, pleasantly decorated waiting room is observed when entering the main door. The décor and furniture appear to be new, clean, and fairly consistent throughout. The chairs were the same style although not all cushions were the same color. A large reception desk is positioned directly across from the main door. It runs the full length of the wall and provides space for multiple receptionists.

The reception desk had educational material including; medical, dental, patient information, discussing options for quality, comprehensive, affordable health care, and WIC information. Behavioral health materials are available but were not in the waiting 
room the day of the environmental scan. Figures $3 \& 4$ show the Latah Clinic waiting room.
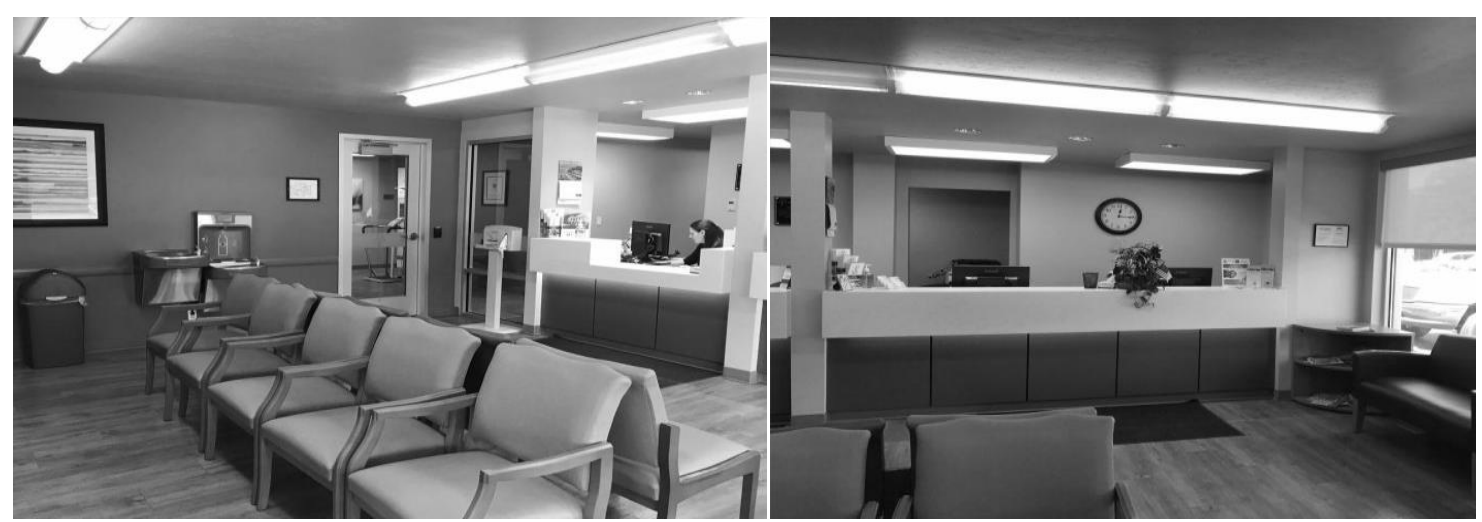

Figures 3 \& 4. Latah Clinic Waiting Room

The entrance to the clinical area for medical, dental and behavioral health is located on the left side of the waiting room. The consult rooms, exam rooms, and dental operatories were located on the periphery of the building. The behavioral health consults rooms are located in the northwest corner of the clinical area. The medical exam rooms, lab, and procedure room were located along the south wall and the dental sterilization room, dental operatories are in the northeast section. The provider "pod" where clinicians from all disciplines have desks is located in the center of the clinical area. Figure 5 is a diagram of the Latah Clinic (not drawn to scale).

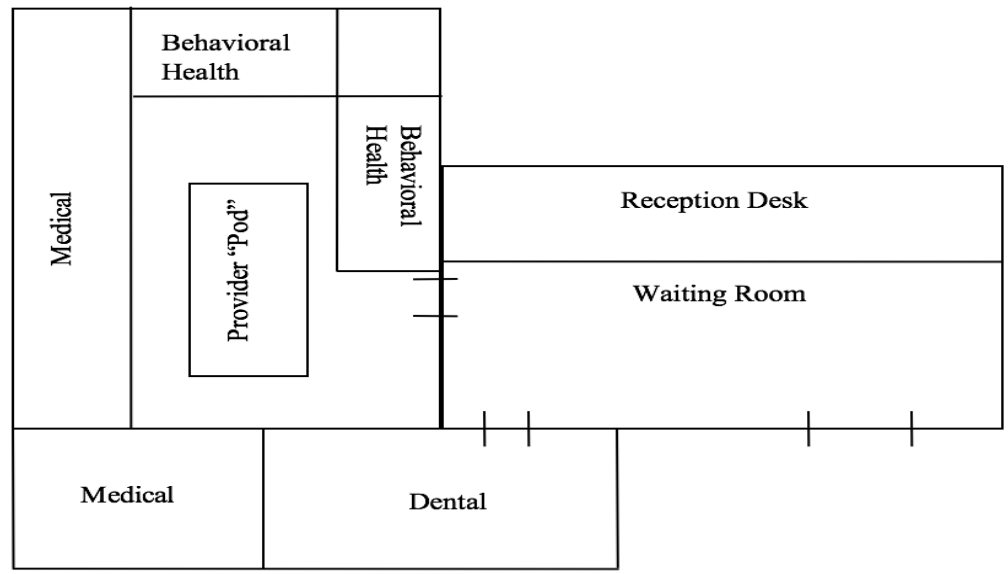

Figure 5. Diagram of Latah Clinic 
The clinic allocated the most space to medical and the least to behavioral health.

All disciplines were provided new equipment when the building was remodeled in late 2015/early 2016. Figures $6,7,8, \& 9$ show the rooms in the clinical area of the clinic.

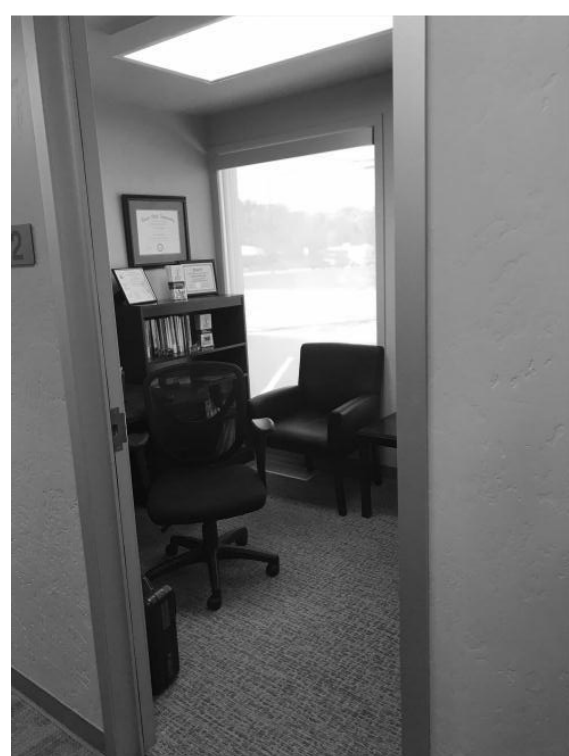

Figure 6. Behavioral Health Consult Room

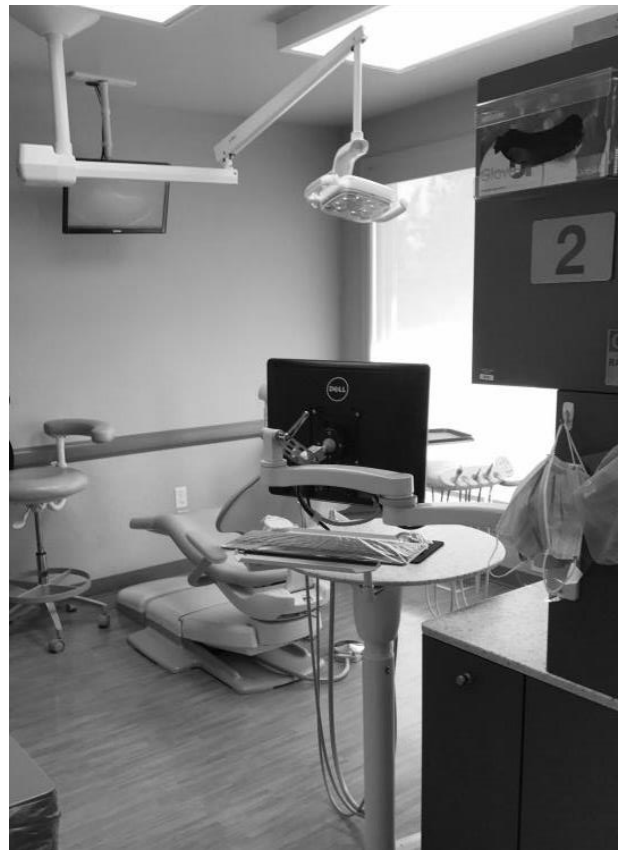

Figure 8. Dental Chair

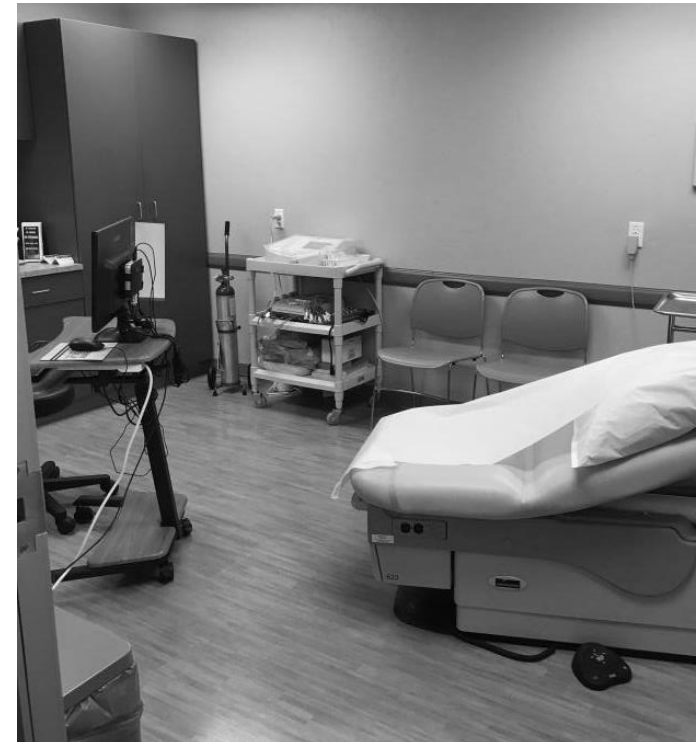

Figure 7. Medical Procedure Room

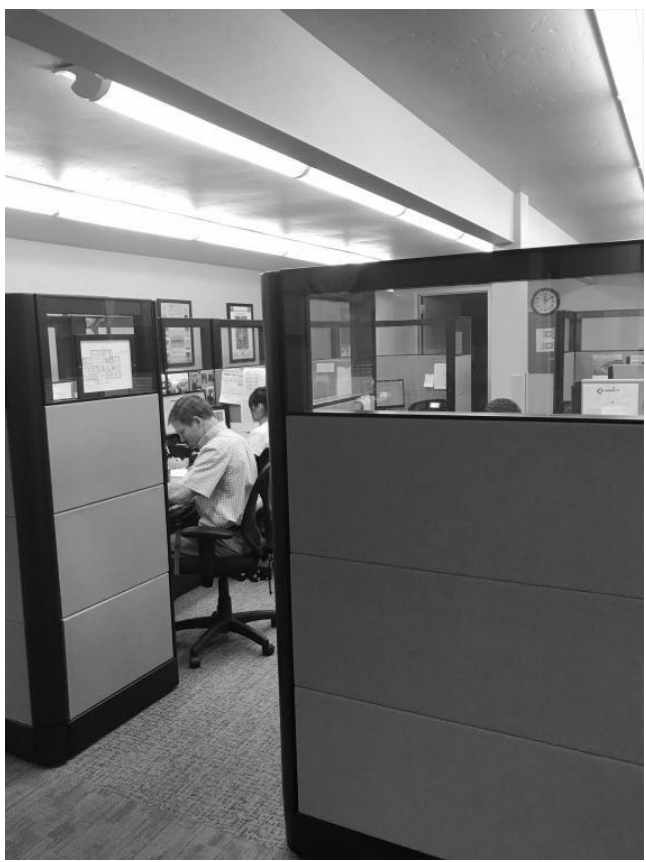

Figure 9. Provider "Pod" 


\section{Intake Forms}

Separate intake forms are provided for patients to complete for each department. Dental and behavioral health forms are completed by hand, by the patient, while the medical form is located in the EMR and information is entered by the provider. The patient registration form can be completed online, prior to the first appointment, or by hand in the office. Only the dental, behavioral health and patient registration forms were made available to the PI.

$\underline{\text { Dental }}$

The dental health history intake form was four pages in length, printed on pink paper, and began by asking “Are you experiencing dental pain?”. The form did not address whether the dental pain was the patient's main concern. The intake form had questions pertaining to each of the three disciplines. There were four questions pertaining to behavioral health, 18 dental health related questions and 54 medical health questions. There was minimal evidence provided in the intake form to suggest it came from an integrated clinic. See Appendix I.

\section{$\underline{\text { Behavioral Health }}$}

The behavioral health history intake form was fourteen pages in length, with five of those pages related to health status. The intake form began with, "Please briefly describe the reason you are here/your current problem(s)". The form included 46 medical history questions for females and 35 for males. In addition, 45 behavioral health questions and no dental health items were included in the form. Medical and behavioral health had a similar proportion of questions pertaining to their department, but the lack of 
dental questions may indicate this intake form does not represent an optimally integrated clinic. See Appendix J.

$\underline{\text { Patient Registration }}$

The patient registration form was two pages in length and could be completed electronically, or in-person at the time of appointment. This form is used for all TRHS clinics. This form requests information pertaining to; general patient information, responsible party, emergency contact, insurance, Boise clinic patient information, family income, ethnicity, race, language, farmworker status, veteran status, sexual orientation, gender identity, interest in reduced fees, healthcare for the homeless information and acknowledgements. The insurance section of this form requests primary and secondary medical insurance and dental insurance. The acknowledgements section of this form also demonstrates an integrated approach regarding consent and health information. When patients sign the registration form, they are; giving consent to TRHS to conduct a medical, dental and or mental health evaluation and make treatment recommendations. Patients are also informed their health information might be shared across the three disciplines. See Appendix K. 


\section{DISCUSSION}

The findings from this study suggest that the Latah Clinic is fully integrated and demonstrates high levels of collaboration. This assessment is based on comparison with the characteristics identified by HRSA through the Oral Health Disparities Collaborative pilot study. The Latah Clinic possessed attributes from five out of the six categories identified by HRSA (NNOHA, 2008). An integrated electronic health record and scheduling system are the aspects from the clinical information systems category that the Latah Clinic has implemented. From the decision support category, Latah has a greater understanding of dental practices among medical staff and has a referral system in place from medical to dental, although referral protocols are not fully utilized. Latah also has integrated care team pods that are a characteristic of the delivery system design category. From the self-management category, the Latah Clinic also has co-located patient education materials. Lastly, integrated staff meetings and co-location of disciplines are aspects relevant to the organization of healthcare category (NNOHA, 2008). These attributes of the Latah Clinic demonstrate a high level of integration.

Resources and barriers are crucial when implementing an integrated model of best fit and no "gold standard" approach exists (Grantmakers in Health, 2012). The differing level of integration at the Latah Clinic versus the other TRHS' clinics also aligns with the research stating that varying levels of integration are due to available resources and barriers (Damiano et al., 2015). Numerous integration approaches have 
been identified because not every clinic presents with the same opportunities. For example, the Latah Clinic secured grant funding to remodel an existing building and implemented an integrated model when it re-opened. Other practices/clinics will have different geographic locations, serve a specific population of need, have established practice norms, and may not have the funding available to implement a highly integrated model.

Despite the small number of participants in this study, the strengths perceived by the key informants were consistent with and supported by literature. During the HRSA Oral Health Disparities Pilot, it was noted that the pilot teams demonstrated that integration benefits the organization, staff, and patients (National Network for Oral Health Access, 2008). Informants identified these integrative strengths; the Latah Clinic is an exemplary model for the organization, providers have a collaborative spirit, and having patients receive comprehensive care in a more effective and efficient manner.

\section{Study Limitations}

This case study had several limitations, including the purposive sampling techniques utilized during this research. TRHS' COO provided the PI with contact information for TRHS employees that were believed to be receptive to being interviewed, which infers a potential volunteer bias. The informants consisted TRHS leadership personnel and department directors. As the directors practiced at Latah, as well as other locations, informant inputs might have been influenced by allegiances with other clinics. If this study was to be replicated, the additions of interviews of full-time Latah Clinic providers and patients from the clinic would offer valuable information. 
The purposive sampling conducted by the COO also led to a small sample size. The initial contact list consisted of seven potential informants. One did not respond to the recruitment email and one did not finish their e-mailed interview, leaving five informants to contribute their views of the integration model at the Latah Clinic. Potential causes as to why the informants could not complete the process, may be; their workload, absence during the study period, or the recipient never received the e-mail messages. In qualitative data, themes arise when multiple informants express the same thought or idea. A small sample size complicates data analysis when documenting themes and limits ability to verify whether the strengths, weaknesses, opportunities and threats presented in this case study reflect those of the overall clinic.

Sending the interview script via e-mail became a limitation for some informants. The e-mail format was provided as an option for informants because it was believed that it was more convenient. As stated earlier, one e-mail interview was never completed. The two that were completed via e-mail responded using short-answers, sometimes one or two words, and lacked the detail that the in-person interviews provided. Due to the e-mail format, the PI was also not able to ask follow-up questions and the richness of a qualitative data collection method was compromised.

As previously mentioned, this study should be replicated with more providers and patients at the Latah Clinic, on a larger scale which includes dental staff, and interviews should be conducted face-to-face, to ensure that the strengths, weaknesses, opportunities and threats reported in this study are valid. However, these limitations are valuable lessons learned for a researcher implementing a similar case study. 


\section{Suggestions}

Based on the data, there are a few suggestions that could further enhance the integration model at the Latah Clinic. These suggestions include; provider expansion, utilization of community resources, development of improved medical-dental referral protocols, the creation of a single integrated health history form, and use of comprehensive evaluation metrics.

Provider expansion was noted as a need for both behavioral health and medical health. According to informants, behavioral health could benefit from another full-time professional and more space for consults. Medical lacks the proper staffing ratio of medical assistants to providers on Wednesdays when there are more providers than usual. Dental could also benefit financially by improving patient flow with the addition of dental staff, and expanding dental from three to five days a week. Utilizing existing community resources such as the Idaho State University (ISU) Dental Residency Program, would provide newly graduated dentists the opportunity to practice in a multidiscipline clinic focused on underserved populations. Establishing a collaborative relationship with ISU would prove to be mutually beneficial to both organizations.

Utilizing community resources in terms of expanding collaboration between the Latah Clinic and other local organizations would help promote greater community awareness of the importance of oral health as part of whole body wellness. For example, collectively working with WIC as well as a referral from Health Services at Boise State University, the Latah Clinic would provide more underserved community members with access to whole body health care which includes dentistry. 
Professional development supported by holding monthly staff meetings dedicated to discussions of "when to refer" to each discipline, could enhance the level of integration at the Latah Clinic. With brief "cross-training" sessions during staff meetings, providers could begin to create holistic treatment plans from dental, behavioral and medical perspectives. Referrals could be initiated earlier, allowing for a timelier intervention and follow-up.

Creation of a single health history form would be beneficial for the clinic and patients. Currently, patients must complete with duplicative information. A single form could save time for the patient, receptionist and provider. The patient would fill out the health history form at the initial appointment, or prior to, and the information could then be added to their chart with universal access to all providers.

Lastly, review existing assessment activities to ensure impact of integration is documented from perspective of patient, clinicians, system and community. The Latah Clinic has shown signs of full integration and can continue to grow and improve with consideration of the aforementioned suggestions. 


\section{CONCLUSIONS}

The purpose of this study was to describe the development and implementation of the TRHS Latah Medical-Dental-Behavioral Health integrated clinic. Although the sample size of key informants was small, the data suggested that the Latah Clinic model has more strengths and opportunities associated with it, than weaknesses or threats. The clinic is collaborative, efficient, comprehensive and has demonstrated evidence of enhancing outcomes. Furthermore, TRHS staff believes that the Latah Clinic continue to expand, improve health outcomes and has the potential to increase the overall health of their patients. The TRHS leadership interviews, Latah Care Team meeting, and environmental scan also demonstrated a fully integrated model with attributes consistent with a high level of collaboration/unification. This represents the progressive and patientcentered characteristics of TRHS.

While the Latah Clinic has only been using this model for 18 months, it has achieved a high level of integration. The leadership team anticipates that the clinic will continue to grow and improve over time as it strives to become as integrated as possible.

Further research needs to be conducted to demonstrate the impact a Latah Clinic model has on health outcomes, communication and collaborations between disciplines, healthcare costs, and patient perceptions of care. This information would more fully enable TRHS to be utilized as a model for other practices, communities, and states that are converting to an integrated model. 


\section{REFERENCES}

Agency for Healthcare Research and Quality (AHRQ). (n.d.). Defining the PCMH. Retrieved from https://pcmh.ahrq.gov/page/defining-pcmh

American Academy of Family Physicians (AAFP). (n.d. a). Primary Care. Retrieved from http://www.aafp.org/about/policies/all/primary-care.html

American Academy of Family Physicians (AAFP). (n.d. b). The Patient-Centered Medical Home (PCMH). Retrieved from http://www.aafp.org/practicemanagement/transformation/pcmh.html

American Dental Association (ADA). (n.d.). Access to Care. Retrieved from http://www.ada.org/en/public-programs/action-for-dental-health/access-to-care

Andersson, K., Furhoff, A., Nordenram, G., \& Wårdh, I. (2007). 'Oral health is not my department'. Perceptions of elderly patients' oral health by general medical practitioners in primary health care centres: a qualitative interview study. Scandinavian Journal of Caring Sciences, 21(1), 126-133 8p.

Bernstein, J., Gebel, C., Vargas, C., Geltman, P., Walter, A., Garcia, R., Tinanoff, N. (2016). Integration of Oral Health into the Well-Child Visit at Federally Qualified Health Centers: Study of 6 Clinics. Retrieved from https://www.cdc.gov/pcd/issues/2016/16_0066.htm

Boulter, S. (2011). Integrating oral health into primary care at the American Academy of Pediatrics. Access, 25(2), 18-20 3p.

Damiano, P. C., Reynolds, J. C., McKernan, S. C., Mani, S., \& Kuthy, R. A. (2015). The 
University of Iowa Public Policy Center. The Need for Defining a PatientCentered Dental Home Model in the Era of the Affordable Care Act. Retrieved from http://ppc.uiowa.edu/sites/default/files/pchdjul2015.pdf

Grantmakers in Health. (2012). Returning the Mouth to the Body: Integrating Oral Health and Primary Care. Retrieved from http://www.gih.org/files/FileDownloads/Returning_the_Mouth_to_the_Body_no4 0_September_2012.pdf

Hall, M. (August 29, 2014). Integrated Care: Healthy Mouth, Healthy Body. Retrieved from http://www.dentistryiq.com/articles/2014/08/integrated-care-healthy-mouthhealthy-body.html

Health Resources and Services Administration (HRSA). (December, 2008). Coming Home: The Patient-Centered Medical-Dental Home in Primary Care Training. Retrieved from https://www.hrsa.gov/advisorycommittees/bhpradvisory/actpcmd/Reports/seventh report.pdf

Health Resources and Services Administration (HRSA). (n.d.). Federally Qualified Health Centers. Retrieved from https://www.hrsa.gov/opa/eligibilityandregistration/healthcenters/fqhc/

Hilton, I. (June 23, 2014). National Network for Oral Health Access. Creating Medical Dental Integration: Helpful Hints and Promising Practices. Retrieved from http://www.nnoha.org/nnoha-content/uploads/2014/06/Creating-Medical-DentalIntegration_2014-06-23.pdf

Institute of Medicine (IOM). (2011). Advancing Oral Health in America. Retrieved from 
https://www.hrsa.gov/publichealth/clinical/oralhealth/advancingoralhealth.pdf Institute of Medicine (IOM) and National Research Council (NRC). (2011). Improving Access to Oral Health for Vulnerable and Underserved Populations. Retrieved from http://www.nationalacademies.org/hmd/ /media/Files/Report\%20Files/2011 /Improving-Access-to-Oral-Health-Care-for-Vulnerable-and-UnderservedPopulations/oralhealthaccess2011reportbrief.pdf

Kandelman, D., Arpin, S., Baez, R. J., Baehni, P. C., \& Petersen, P. E. (October 01, 2012). Oral health care systems in developing and developed countries. Periodontology 2000, 60, 1.

Lewis, C. W., Barone, L., Quinonez, R. B., Boulter, S., \& Mouradian, W. E. (2013). Chapter oral health advocates: A nationwide model for pediatrician peer education and advocacy about oral health. International Journal of Dentistry, 2013, 498906. http://doi.org/10.1155/2013/498906

Monajem, S. (2006). Integration of oral health into primary health care: the role of dental hygienists and the WHO stewardship. International Journal of Dental Hygiene, 4(1), $47515 \mathrm{p}$.

Munger, R. (April 17, 2012). "Evolving oral health models: lesson learned from behavioral health", presentation at the Grantmakers in Health Issue Dialogue Returning the Mouth to the Body: Integrating Oral Health and Primary Care. Retrieved from http://www.gih.org/files/FileDownloads/Returning_the_Mouth_ to_the_Body_no40_September_2012.pdf

Nasseh, K., Greenberg, B., Vujicic, M., \& Glick, M. (2014). The effect of chairside chronic disease screenings by oral health professionals on health care costs. Am J 
Public Health, 104(4), 744-50. Doi: 10.2105/AJPH.2013.301644.

National Network for Oral Health Access (NNOHA). (2008). Oral Health Disparities Collaborative Implementation Manual. Retrieved from http://www.nnoha.org/nnoha-content/uploads/2013/09/OHDC-ImplementationManual-with-References.pdf

Office of Disease Prevention and Health Promotion. (n.d.). Oral Health. Retrieved from https://www.healthypeople.gov/2020/leading-health-indicators/2020-lhitopics/Oral-Health

Pew Center on the States. (2012). A Costly Dental Destination: Hospital Care Means States Pay Dearly. Retrieved from http://www.pewtrusts.org/ /media/assets/2012 /01/16/a-costly-dental-destination.pdf

Powell, V., \& Din, F. (2008). Call for an Integrated (Medical/Dental) Health Care Model that Optimally Supports Chronic Care, Pediatric Care, and Prenatal Care as a Basis for $21^{\text {st }}$ Century EHR Standard and Products: EHR Position Paper. Retrieved from http://www.himss.org/sites/himssorg/files/HIMSSorg/policy/d/hc_comm_discussi on/MoonTownshipPennPositionPaper.pdf

Rabiei, S., Mohebbi, S. Z., Patja, K., \& Virtanen, J. I. (January 01, 2012). Physicians' knowledge of and adherence to improving oral health. BMC Public Health, 12. Raybould, T. P., Wrightson, A. S., Massey, C. S., Smith, T. A., \& Skelton, J. (November 01, 2009). Advanced General Dentistry program directors' attitudes on physician involvement in pediatric oral health care. Special Care in Dentistry, 29, 6, 232236. 
Rhode Island Health Center Association (RIHCA). (2011). Patient Centered Medical-

Dental Home Initiatives: A Survey of Current and Future Strategies to Coordinate Care in Rhode Island. Retrieved from http://www.rihca.org/pdfs/Patient\%20Centered\%20Medical\%20Dental\%20Home \%20Survey\%20Report.pdf

Riter, D., Maier, R., \& Grossman, D. (2008). Delivering preventative oral health services in pediatric primary care: A case study. Health Affairs, 27, 6, 1728-1732.

Rogers, J., Stewart, P., Stapleton, J., Hribar, D., Adams, P., \& Gale, A. (2000). An interdisciplinary approach to the management of complex medical and dental conditions. Australian Dental Journal 2000; 45;(4):270-276.

Substance Abuse and Mental Health Services Administration(SAMHSA)-Health Resources and Services Administration (HRSA) Center for Integrated Health Solutions (CIHS). (2013). CIHS' Standard Framework for Levels of Integrated Healthcare. Retrieved from http://www.integration.samhsa.gov/integrated-caremodels/A_Standard_Framework_for_Levels_of_Integrated_Healthcare.pdf

Simon, L. (2016). Overcoming historical separation between oral and general health care: Interprofessional collaboration for promoting health equity. AMA Journal of Ethics, 18, 9, 941-949. Retrieved from http://journalofethics.amaassn.org/2016/09/pdf/pfor1-1609.pdf

Smiley, C. (2013). Dental Quality Alliance. The Importance of Patient-Centered Care. Retrieved from http://www.ada.org/ /media/ADA/Education\%20and\%20Careers /Files/Session_2_Smiley.pdf?la=en 
Thema, L. K., \& Singh, S. (2013). Integrated primary oral health services in South Africa: The role of the PHC nurse in providing oral health examination and education. African Journal of Primary Health Care \& Family Medicine, 5(1), 1-4. Retrieved from http://libproxy.boisestate.edu/login?url=http://search.proquest. Com.libproxy.boisestate.edu/docview/1738751622? accountid=9649

Tomar, S. L., \& Cohen, L. K. (June 02, 2010). Attributes of an ideal oral health care system. Journal of Public Health Dentistry, 70, 1.

Terry Reilly Health Services. (2015). 2015 Annual Report. Retrieved from http://www.trhs.org/app/uploads/2016/11/AR-2016-Final-Digital.pdf

Terry Reilly Health Services. (n.d.). About Us. Retrieved from http://www.trhs.org

World Health Organization (WHO). (2003). The World Oral Health Report 2003. Retrieved from http://www.who.int/oral_health/media/en/orh_report03_en.pdf 
APPENDIX A

Recruitment Message 
Subject line: Requesting Permission to Interview

Greetings ___ (TRHS employee name)___,

Hello, my name is Kylie Pace and I am conducting a qualitative study of Terry Reilly Health Services (TRHS) Latah Clinic in an effort to document the implementation of the medical-dental-behavioral health "home". The results of this study will be shared with TRHS employees and eventually published in a peer-reviewed journal in order to facilitate greater understanding of the process of health services integration into a "home" model.

I am requesting your permission to join me in a conversational interview. Interview dates are being set for April 10, 2017 until April 24, 2017. The interview should last approximately 45 minutes. Participation is voluntary, confidential and your responses will be anonymous. If you wish to participate, I will send an informed consent document for you to read and sign. Please complete and email these forms back within 3 days. Along with the completed informed consent forms, please indicate whether it would be easier and more effective for you to be interviewed through email, over the phone or in person. If phone or in person interviews work best for you, I will reach out via e-mail with date and time options for the interview to take place and request that you indicate which date/time combination would work for your schedule.

If you have any questions, contact myself at kyliepace@u.boisestate.edu or my coinvestigator, Dr. Sarah Toevs at stoevs@boisestate.edu.

Thank you for your time,

Kylie Pace

Graduate Student, Master of Health Science Program

Boise State University 
APPENDIX B

Informed Consent 


\section{Study Title: Integration of Medical \& Dental Services: Case Study of the TRHS Latah Clinic Experience \\ Principal Investigator: Kylie Pace Co-Investigator: Dr. Sarah Toevs}

This consent form will give you the information you will need to understand why this research study is being done and why you are being invited to participate. It will also describe what you will need to do to participate as well as any known risks, inconveniences or discomforts that you may have while participating. We encourage you to ask questions at any time. If you decide to participate, you will be asked to sign this form and it will be a record of your agreement to participate. You will be given a copy of this form to keep.

\section{Purpose and Background}

You are invited to participate in a research study designed to describe the development and implementation of the Terry Reilly Health Services (TRHS) Latah medical-dentalbehavioral health integrated clinic (Latah Clinic).

You are being asked to participate because you were identified as a key informant at TRHS or the Latah Clinic.

\section{$>$ Procedures}

If you agree to be in the study, you will complete the informed consent paperwork within 3 days of receiving the initial recruitment e-mail. Along with the completed informed consent forms, you will indicate whether it would be easier and more effective for you to be interviewed through e-mail, over the phone or in person. If phone or in person interviews work best, then please indicate which of the provided dates and times, found within the recruitment e-mail, would work for you.

The interviews could last anywhere from fifteen to sixty-minutes, depending on the detail that you provide. During the interviews, the PI will take notes during in-person or over the phone interviews, and highlight important aspects of e-mailed interviews. The PI will be looking for similarities and differences between the key informant responses. These notes will be maintained in a secure Boise State University shared drive accessible to only the PI and Co-Investigator.

At the conclusion of data collection, the PI will compile the findings and describe the development and implementation of the Terry Reilly Health Services (TRHS) Latah medical-dental-behavioral health integrated clinic.

\section{$>$ RISKS}

There are no potential research risks to participants.

\section{BENEFITS}

There will be no direct benefit to you from participating in this study. However, the information that you provide will contribute to the detailed story of the Latah integrated 
clinic and whether the model would be viable elsewhere. The strengths and weaknesses that are identified during this research could shape future integration efforts.

\section{EXTENT OF CONFIDENTIALITY}

Reasonable efforts will be made to keep the personal information in your research record private and confidential. Any identifiable information obtained in connection with this study will remain confidential and will be disclosed only with your permission or as required by law. The members of the research team and the Boise State University Office of Research Compliance (ORC) may access the data. The ORC monitors research studies to protect the rights and welfare of research participants.

Your name will not be used in any written reports or publications which result from this research, unless you have given explicit permission for us to do this (remove if not applicable to your study). Data will be kept for three years (per federal regulations) after the study is complete and then destroyed.

\section{$>$ PAYMENT/COMPENSATION}

There is no payment or compensation associated with participation in this study.

\section{PARTICIPATION IS VOLUNTARY}

You do not have to be in this study if you do not want to. If you volunteer to be in this study, you may withdraw from it at any time without consequences of any kind or loss of benefits to which you are otherwise entitled.

\section{QUESTIONS}

If you have any questions or concerns about your participation in this study, you should first contact the principal investigator at kyliepace@u.boisestate.edu or (707) 382-9054 or Dr. Toevs at stoevs@ boisestate.edu.

If you have questions about your rights as a research participant, you may contact the Boise State University Institutional Review Board (IRB), which is concerned with the protection of volunteers in research projects. You may reach the board office between 8:00 AM and 5:00 PM, Monday through Friday, by calling (208) 426-5401 or by writing: Institutional Review Board, Office of Research Compliance, Boise State University, 1910 University Dr., Boise, ID 83725-1138. 


\section{DOCUMENTATION OF CONSENT}

I have read this form and decided that I will participate in the project described above. Its general purposes, the particulars of involvement and possible risks have been explained to my satisfaction. I understand I can withdraw at any time. I have received a copy of this form.

Printed Name of Study Participant

Signature of Study Participant

Date 
APPENDIX C

Latah Clinic Key Informant Interview Script 
"Thank you for taking the time out of your schedule to take part in this research study. Your input is extremely valuable. Today I am going to ask you questions pertaining to your perceptions of the strengths and weaknesses associated with the medical-dental-behavioral "home" model implemented at the Latah Clinic. But first, I am going to ask some background questions.

For starters,

What is your employment history with TRHS?

Have you worked elsewhere with the same type of job responsibilities? If yes, is your role at the Latah Clinic different? If yes, how?

How would you describe operation of the Latah Clinic?

Now I am going to ask you several questions about strengths and weaknesses regarding the integrated model.

What do you see as strengths of the Latah Clinic regarding practice processes (For example: patient flow from one department to another, intake process, scheduling system, referral system, what takes place during a new patient exam, etc.)? What do you see as weaknesses of the Latah Clinic regarding practice processes? What do you see as the strengths of the Latah Clinic regarding patient outcomes? What do you see as weaknesses of the Latah Clinic regarding patient outcomes? From your perspective, what opportunities in the new multi-specialty delivery system (home) could be used to enhance the success of the Latah Clinic? For example, new services, improved outcomes due to multi-specialty in-house collaboration.

From your perspective, are there any threats to TRHS that could diminish the success of the Latah Clinic? For example, new government policies due to the new administration, local economic changes, etc.

And now my final question is asking for your recommendation.

If someone were to replicate how the Latah Clinic operates, in another setting, what would you recommend that they keep the same? And what would you recommend that they make changes to?

Do you have any other comments you would like to share?

This is the conclusion of our interview and I want to thank you again for sharing your insights on the development and implementation of the Terry Reilly Health Services Latah medical-dental-behavioral health integrated clinic." 
APPENDIX D

TRHS Leadership Key Informant Interview Script 
"Thank you for taking the time out of your schedule to take part in this research study. Your input is extremely valuable. Today I am going to ask you questions that will help me describe the history of TRHS Latah Clinic and how it operates.

First, can you give me a little background on TRHS and how it was established? When did the Latah Clinic open? And what services were available?

Has the Latah Clinic always been an integrated facility as it is today?

The following questions are going to give me a better understanding as to the level of integration at the Latah Clinic.

Is there a facilitated, formalized referral system between providers that would allow for better tracking and follow-up with patients in place? (Least integrated) If yes, how does this process function? If no, do you see this being implemented in the future? Why?

Is there a common electronic health record (EHR) system that can be seen by both dental and medical professionals in place at Latah? (Virtual integration) If yes, how does this process function? If no, do you see this being implemented in the future? Why?

Is there a payer model in place where dental and medical professionals share the same financial risks and opportunities for a shared group of patients? (Financial sharing) If yes, how does this process function? If no, do you see this being implemented in the future? Why?

Do dental and medical providers work within the same building at Latah but operate separately and not coordinate care? (Co-location) If yes, how does this process function? If no, do you see this being implemented in the future? Why? Is the dentist a part of an inter-professional group of providers that practice at a single location, collaboratively, in order to provide comprehensive care to their patients? (Highest integrated model) If yes, how does this process function? If no, do you see this being implemented in the future? Why?

Based off your answers to the previous five questions, how would you describe the level of integration at the Latah Clinic?

Is this level of integration different than the other TRHS clinics? If yes, how?

Why?

From your perspective, what were the opportunities that made the integration of the Latah clinic possible?

And lastly, I want to ask what do you see in the future for the Latah Clinic? How do you anticipate the model being used at Latah to impact other TRHS Clinics?

Do you have any other comments you would like to share?

This is the conclusion of our interview and I want to thank you again for sharing your insights on the development and implementation of the Terry Reilly Health Services Latah medical-dental-behavioral health integrated clinic." 
APPENDIX E

Latah Clinic Care Team Meeting Observations Checklist 
Note the observations made during the meeting in regard to the following;

Structure of the meeting

Meeting location

Seating arrangement during the meeting

Is there an obvious leader?

$\square \quad$ Was every voice heard during the meeting?

$\square \quad$ Length of the meeting

$\square \quad$ What was the focus of the meeting?

- Single or multiple focuses?

- Patient or process based? 
APPENDIX F

Latah Clinic Care Team Meeting Agenda 


\begin{tabular}{|c|c|}
\hline REILLY & Latah Care Team Agenda \\
Date and Time: May 2, 2017 & Location: Latah \\
\hline Your tealth. Our Mission. & \\
\hline
\end{tabular}

Recorder: Al

TimeKeeper:

Care Team Members:

Guests:

Workgroup Folder Location: ..ICare Team Mtg Agenda and Minutes

\begin{tabular}{|c|c|c|c|c|}
\hline & Topic & Discussion (Leader) & Decision & Responsibility \\
\hline 1. & Welcome & 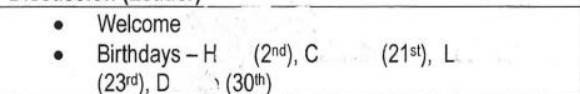 & . & \\
\hline 2. & Corporate Updates & $\begin{array}{ll} & \text { Introduce Latah Super Users }-\mathrm{K} \\
& \mathrm{C}, \mathrm{Y}, \mathrm{M} \\
-\mathrm{T} & \mathrm{T} \\
-\mathrm{Y}\end{array}$ & & \\
\hline 3. & $\begin{array}{l}\text { Patient-Centered Access } \\
\text { (Topics may include-clinician schedules; office } \\
\text { hours, after hours, electronic access, Urgent } \\
\text { care/Walk-ins, Triage, Outreach. Communication) }\end{array}$ & $\begin{array}{l}\text { No show policy changes. } \\
\text { - Phone tree changes eff May } 8 .\end{array}$ & & \\
\hline 4. & $\begin{array}{l}\text { Team-Based Care } \\
\text { (Topics may include - Huddles, TR Care Plans for } \\
\text { specific patients, Individual patient/provider issues, } \\
\text { workflow (including front desk check-in, nursing } \\
\text { rooming protocol), Behavioral Health Integration) }\end{array}$ & $\begin{array}{l}\text { - Homeless Grant Patients refilling meds too early and } \\
\text { sharing with family/friends (Dr. K } \\
\text { - Metformin patients - we need to check CBC } \\
\text { annually to watch for Megaloblastic Anemia (Dr. } \\
\text { K } \\
\text { - BHC overview for new staff/refresher (E ) }\end{array}$ & & \\
\hline
\end{tabular}




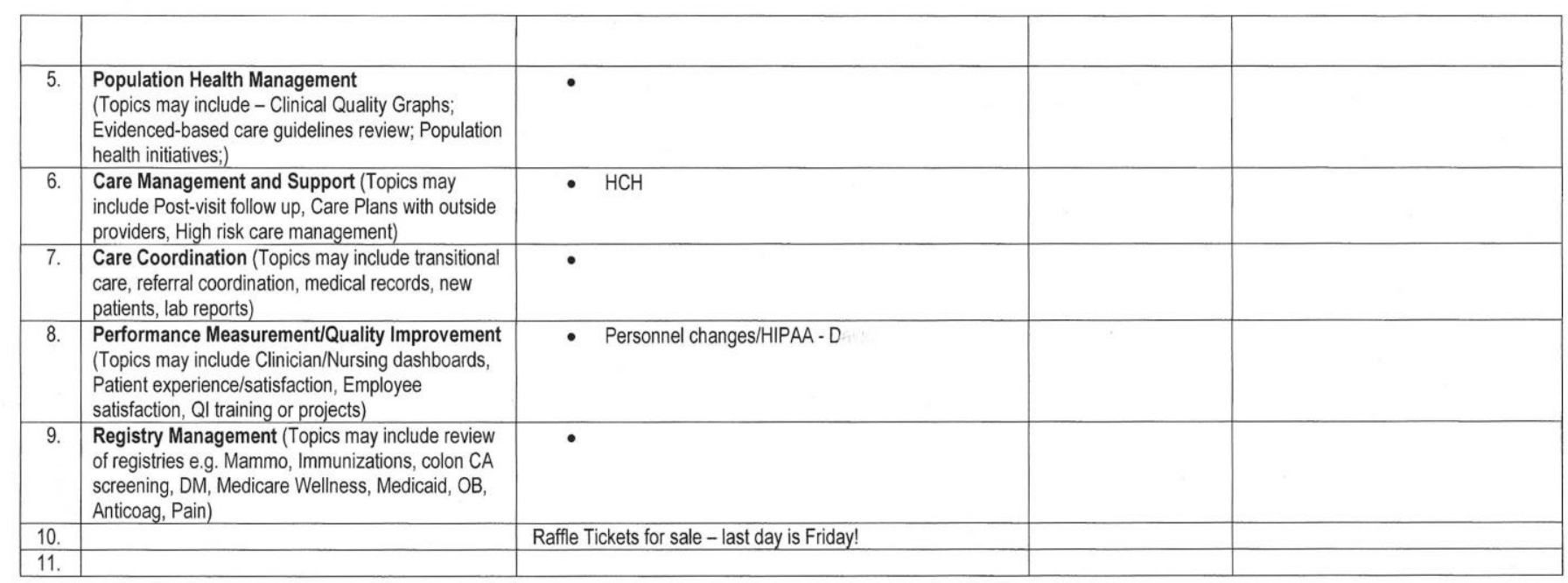

Next Meeting: 
APPENDIX G

Environmental Scan Checklist 
Document the following factors for the environmental scan;

$\square$ General structure/layout of the clinic

Location of receptionist

$\square \quad$ Is there consistent décor/furniture?

$\square$ Is there an equivalent proportion of space allocated for each department?

$\square \quad$ Is there an obvious divide between the departments?

$\square \quad$ State of the equipment in each department?

$\square$ Educational material in the waiting room for each department? 
APPENDIX $\mathrm{H}$

Intake Forms Checklist 
Document the following for the intake forms;

The same intake form for all departments (dental, medical and behavioral health)

$\square \quad$ An even distribution of questions for all services

- Medical related health questions

- Dental related health questions

- Behavioral related health questions

What is their main concern

$\square$ Proof of integration 
APPENDIX I

Dental Intake Form 


\section{Dental Health History}

Patient Name:

Date of Birth:

Please answer all of the following questions by circling YES or NO.

\begin{tabular}{|l|l|l|}
\hline Are you experiencing dental pain? & Yes (see below) & No \\
\hline
\end{tabular}

Please rate your pain intensity today between $1-10$

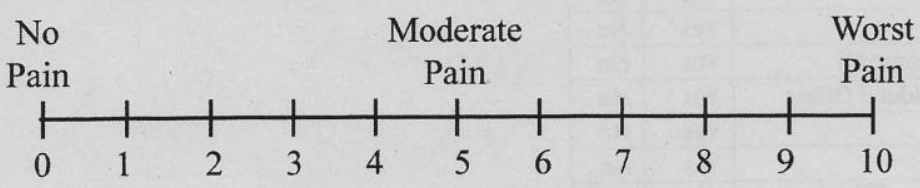

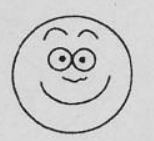

0

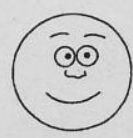

2

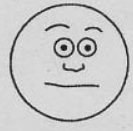

4

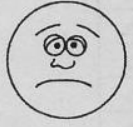

6

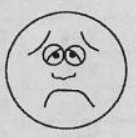

8

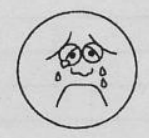

10

\begin{tabular}{|l|l|l|}
\hline Is it possible that you are pregnant? & Yes & No \\
\hline Are you allergic to latex? & Yes & No \\
\hline Are you allergic to nickel, acrylic or other? & Yes & No \\
\hline Have you ever had any bleeding that required treatment? & Yes & No \\
\hline Are you under the care of a medical doctor? & Yes & No \\
\hline Have you been hospitalized in the last 5 years? & Yes & No \\
\hline Current or Past Osteoporosis Therapy or other Bisphosphonates? & Yes & No \\
\hline Have you taken the following medications: Fosamax, Actonel, Boniva? & Yes & No \\
\hline $\begin{array}{l}\text { Do you smoke? } \\
\text { If yes; how much per day? }\end{array}$ & Yes & No \\
\hline $\begin{array}{l}\text { Do you use smokeless tobacco? } \\
\text { If yes; how much per day? }\end{array}$ & For how long? & No \\
\hline $\begin{array}{l}\text { Alcohol use? } \\
\text { If yes; how much per day? }\end{array}$ & Yes how long? & No \\
\hline $\begin{array}{l}\text { Drug use? } \\
\text { If yes; what drugs? }\end{array}$ & Yes & No \\
\hline $\begin{array}{l}\text { For how long? } \\
\text { In the last } 2 \text { weeks, have you felt Depressed or sad mood, most of the } \\
\text { day, nearly every day? }\end{array}$ & Yes & No \\
\hline $\begin{array}{l}\text { In the last } 2 \text { weeks, have you felt diminished interest/pleasure in } \\
\text { activities most of the day? }\end{array}$ & Yes & No \\
\hline
\end{tabular}


STERRY

Patient Name:

\section{Dental Health History}

Date of Birth

Please answer all of the following questions by circling YES or NO.

Do you have or have you ever had any of the following?

\begin{tabular}{|l|l|l|}
\hline Active Heart Murmur & Yes & No \\
\hline Alcohol or Substance Abuse & Yes & No \\
\hline Anemia (Bleeding Problem / Other blood disease) & Yes & No \\
\hline Angina (Chest Pain) & Yes & No \\
\hline Arrhythmias (Irregular Heart Beat) & Yes & No \\
\hline Arthritis (Osteo or Rheumatoid) & Yes & No \\
\hline Artificial Heart Valve (Heart Valve Replacement) & Yes & No \\
\hline Artificial Joints (Hip / Knee /Ankle / Shoulder / Other & Yes & No \\
\hline Asthma & Yes & No \\
\hline Blood Aids or HIV Virus & Yes & No \\
\hline Blood Disorders & Yes & No \\
\hline Blood Transfusions & Yes & No \\
\hline Breathing or Respiratory Problems & Yes & No \\
\hline Cancer & Yes & No \\
\hline Cold Sores & Yes & No \\
\hline Coronary Heart Disease & Yes & No \\
\hline Diabetes & Yes & No \\
\hline Heart Attack & Yes & No \\
\hline Heart Defects & Yes & No \\
\hline Heart Surgery & Yes & No \\
\hline Hemophilia & Yes & No \\
\hline Hepatitis (A,B,C or other) & Yes & No \\
\hline High Blood Pressure & Yes & No \\
\hline History of Paresthesia & Yes & No \\
\hline Kidney Disease & Yes & No \\
\hline Kidney Stones & Yes & No \\
\hline Liver Disease & Yes & No \\
\hline Mitral Valve Prolapse & Yes & No \\
\hline Neurological Disorders & Yes & No \\
\hline Oral Herpes & Yes & No \\
\hline Pacemaker (or Defibrillator) & Yes & No \\
\hline Scarlet Fever & Yes & No \\
\hline Seizures / Epilepsy & Yes & No \\
\hline Shunts & Yes & No \\
\hline Sickle Cell Anemia & Yes & No \\
\hline Sinus Problems & Yes & No \\
\hline Stroke & Yes & No \\
\hline Surgical Prosthesis & Yes & No \\
\hline Thyroid & Yes & No \\
\hline Tumors & Yes & No \\
\hline & & \\
\hline
\end{tabular}

Updated Date: 


\section{Dental Health History}

Patient Name:

Date of Birth:

\begin{tabular}{|l|l|l|}
\hline $\begin{array}{l}\text { Do you have any disease, conditions } \\
\text { or problems not listed here? } \\
\text { Please list. }\end{array}$ & & \multirow{2}{*}{ For Office Use Only: } \\
\hline $\begin{array}{l}\text { Please list any hospitalizations and } \\
\text { surgeries }\end{array}$ & & \\
\hline $\begin{array}{l}\text { Do you have any allergic reactions to } \\
\text { medications or latex? Please circle all } \\
\text { that apply. }\end{array}$ & $\begin{array}{l}\text { Latex Penicillin or other antibiotics } \\
\text { Aspirin Codeine Metal lodine }\end{array}$ & \\
\hline Are you currently taking any prescription medication, over the counter items or herbal supplements? If so, please list: \\
\hline Name & Local anesthetics such as Lidocaine & \\
\hline & & Reason for taking \\
\hline & & \\
\hline & & \\
\hline & & \\
\hline & & \\
\hline & & \\
\hline & & \\
\hline & & \\
\hline & & \\
\hline & & \\
\hline & & \\
\hline & & \\
\hline & & \\
\hline
\end{tabular}

Updated Date: 


\section{Dental Health History}

Patient Name:

Date of Birth:

\begin{tabular}{|l|l|l|}
\hline Do you have regular dental checkups? & \multicolumn{2}{l|}{ Date of last exam: } \\
\hline Have you had any trouble with previous dental treatment? & \multicolumn{2}{l|}{ If yes, please explain: } \\
\hline Have you noticed any lumps or sores in your mouth? & Yes & No \\
\hline Do your gums bleed when you brush your teeth? & Yes & No \\
\hline Do you clench or grind your teeth? & Yes & No \\
\hline Do you have any pain in the mouth, face, eyes, neck or throat? & Yes & No \\
\hline Have you had injuries to your face, jaw or teeth? & Yes & No \\
\hline Are you unhappy with the look of your teeth and/or smile? & & Yes \\
\hline How many times a day do your brush? & & \\
\hline How many times a day do you floss? & \\
\hline
\end{tabular}

Please answer the following questions for all children

\begin{tabular}{|l|l|l|l|}
\hline Do they suck their thumb or finger? & Yes & No \\
\hline Do they use fluoride toothpaste? & Yes & No \\
\hline $\begin{array}{l}\text { Do they use any other fluoride products, like mouthwash or } \\
\text { prescription fluoride? }\end{array}$ & Yes & No \\
\hline Does a parent or adult help them brush? & Yes & No \\
\hline $\begin{array}{l}\text { Do they eat sugary foods and/or snacks? } \\
\text { If yes, what and how much? }\end{array}$ & Yes & No \\
\hline $\begin{array}{l}\text { Do they drink anything besides water or milk? } \\
\text { If yes, what and how much? }\end{array}$ & \\
\hline $\begin{array}{l}\text { Yes } \\
\text { yes }\end{array}$ & \\
\hline
\end{tabular}

Please answer the following for children ages $0-5$ years

\begin{tabular}{|l|l|}
\hline $\begin{array}{l}\text { Is or was the child given a bottle or Sippy-cup to suck on } \\
\text { to fall asleep? }\end{array}$ & Yes No \\
\hline
\end{tabular}


APPENDIX J

Behavioral Health Intake Form 


\section{Adult Intake Questionnaire}

Please take enough time to complete this questionnaire thoroughly, but be brief with your responses when possible. Feel free to put 'N/A' when 'not applicable' a question mark if 'not known,' or simply check-mark the space in response to yes/no questions; but please do not respond to everv item medical record accuracy and completeness make for a good foundation for successful treatment. Know that we honor your confidentiality; consequently, you can be sure that none of your medical record information, including that provided on this form, will be released without your full knowledge and/or expressed consent. Thank you.

How did you hear about us?

Please briefly describe the reason you are here/ your current problem(s):

\section{Past Psychiatric History:}

How old were you when you first encountered mental health services and what compelled your referral or involvement at that time?

Have you undergone previous counseling?__ When (how old were you)?_Reason?

Please list what, if any, psychiatric medications you have taken in the past: None?

1)

2)

3)

4)

5)

6)

Please list your current psychiatric medications (by name and amount taken each day):

1)

2)

3)

4)

6)

Have you been hospitalized for psychiatric reasons? _ No _ Yes... and how many times?

When (age, grade or date is fine) were you first psychiatrically hospitalized and why?

When most recently and why?

Have you any past suicide attempts? ___ No __ Yes, and how many times?

If yes, by what method?

If you have attempted suicide more than once, how old were you when first attempted, and when last? 


\section{$\underline{\text { Safety Issues }}$}

Do you have access to any of the following?

Large quantities of medications

Firearms or other weapons: (list which types)

Do you have any other safety issue we should know about?

\section{Family History:}

Do any members of your immediate or extended family have psychiatric illness? If so, can you name the diagnoses?

\section{Medical History:}

List any surgeries you've had:

List any chronic medical illness you know you have(i.e. asthma, arthritis, diabetes, high blood pressure, etc.):

List any non-psychiatric medications you are currently taking for medical problems:

1)

2) 3)

4)

5)

Have you any known allergies to medications/which?

\section{Psychosocial History:}

Born Where (State)? Raised by biological parents or otherwise?

If your parents separated/divorced, approximately how old were you?

Childhood: OK? Not OK if not, briefly state why?

History of having been physically abused: Yes ___ No

If yes, briefly explain over what age period \& by whom: 
History of having been sexually abused : __ Yes __ No

If yes, briefly explain over what age period \& by whom:

\section{Drug/Alcohol History:}

Drug or Alcohol Use? N__ No Yes/Which Substances:

If so, beginning approximately when (at what age or grad in school)?

Have you ever been in substance abuse treatment? __ No __ Yes

If yes, outpatient or inpatient and at what age?

\section{Tobacco History:}

Never Smoked:

Current Smoker: ___ Yes _ No

If yes, please answer the following:

How often?

Some Days

Every Day

How much?

__ Less than one pack per day ___ One pack per day

_ Two packs per day ___ More than two packs per day

Former Smoker:

Yes No No

How long ago did you quit:

How often did you smoke?

Some Days

Every Day

Page 11 of 13 
How much did you smoke?

Less than one pack per day

One pack per day

_ Two packs per day ___ More than two packs per day

\section{Legal History:}

Please describe any legal problems you have or have had:

\section{Educational History:}

High School Graduate: ___ Yes ___ No Last Grade Attended:

GED: __ Yes_ _ No
Special Education:_Yes _ No
College: _ Y Yes_ N No

\section{Employment History:}

Employed now? __ Yes __ No Year Last Employed:

Past types of employment/work performed:

Adult Relationships: Please Circle:

Please Circle: Single/Divorced/Widowed/Partnered/Married/Remarried

If divorced and remarried, at what age and how many times?

How many children have you?

With whom do you live, and how are you supported at present?

\section{For Office Use Only}

Diagnosis:

Initial Tx: 
Today's Date:

Health History

Name

Age

Birth Date

Occupation Last Physical Examination Date

Are you allergic to any medications? If yes, please list them

Have you or any member of your family been diagnosed with any of the following conditions? List affected family member, if applicable.

Abnormal Electrocardiogram

Cancer-where and what type

Cataracts/Glaucoma

Colon or Bowel Trouble

Diabetes

Epilepsy

Heart Murmur as Adult

Heart Attack

High Blood Pressure

Kidney Disease

Kidney Stones

Liver disease

Lung disease

Nervous system disorder

Poor Blood Clotting

Skin Condition

Stomach or Duodenal Ulcer

Sexually Transmitted Disease

Thyroid Disorder

Men

Prostate problems

Women

Menstrual Difficulties

Cystitis

Ovarian Cyst

Other Gynecological Problems

Still Menstruating? Yes/No

Age period started

Number of children

Self Family Date
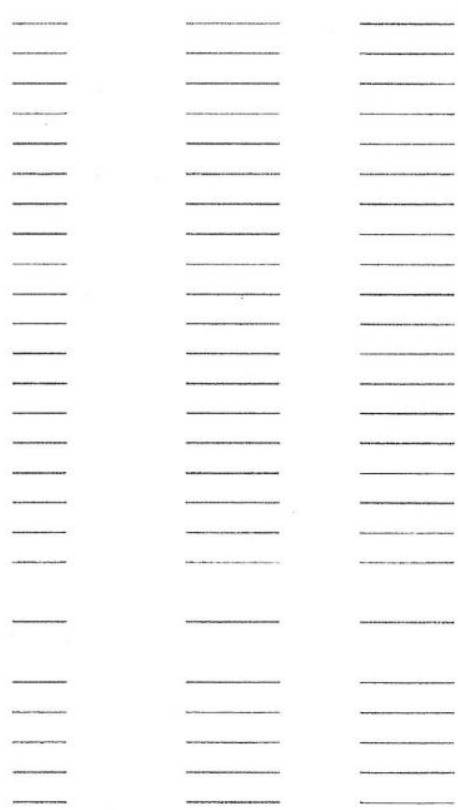

Age period stopped

Number of pregnancies Number of miscarriages

Is there any chance you may be pregnant?

Hospitalizations/Reasons with date's

Page 13 of 13 
DSM-5 Self-Rated Level 1 Cross-Cutting Symptom Measure-Adult

Name:

Age:

Sex: $\square$ Male $\square$ Female Date:

If this questionnaire is completed by an informant, what is your relationship with the individual? In a typical week, approximately how much time do you spend with the individual? hours/week

Instructions: The questions below ask about things that might have bothered you. For each question, circle the number that best describes how much (or how often) you have been bothered by each problem during the past TWO (2) WEEKS.

\begin{tabular}{|c|c|c|c|c|c|c|c|}
\hline & $\begin{array}{l}\text { During the past TWO (2) WEEKS, how much (or how often) have you been } \\
\text { bothered by the following problems? }\end{array}$ & $\begin{array}{c}\text { None } \\
\text { Not at } \\
\text { all }\end{array}$ & \begin{tabular}{|c|} 
Slight \\
Rare, less \\
than a day \\
or two \\
\end{tabular} & \begin{tabular}{|c|} 
Mild \\
Several \\
days
\end{tabular} & \begin{tabular}{|c|}
$\begin{array}{c}\text { Moderate } \\
\text { More than }\end{array}$ \\
half the \\
days
\end{tabular} & \begin{tabular}{|c|} 
Severe \\
Nearly \\
every \\
day \\
\end{tabular} & \begin{tabular}{|c|} 
Highest \\
Domain \\
Score \\
(clinician) \\
\end{tabular} \\
\hline \multirow[t]{2}{*}{ t. } & 1. Little interest or pleasure in doing things? & 0 & 1 & 2 & 3 & 4 & \\
\hline & 2. Feeling down, depressed, or hopeless? & 0 & 1 & 2 & 3 & 4 & \\
\hline 11. & 3. Feeling more irritated, grouchy, or angry than usual? & 0 & 1 & 2 & 3 & 4 & \\
\hline \multirow[t]{2}{*}{ III. } & 4. Sleeping less than usual, but still have a lot of energy? & 0 & 1 & 2 & 3 & 4 & \\
\hline & $\begin{array}{l}\text { 5. Starting lots more projects than usual or doing more risky things than } \\
\text { usual? }\end{array}$ & 0 & 1 & 2 & 3 & 4 & \\
\hline \multirow[t]{3}{*}{ IV. } & 6. Feeling nervous, anxious, frightened, worried, or on edge? & 0 & 1 & 2 & 3 & 4 & \\
\hline & 7. Feeling panic or being frightened? & 0 & 1 & 2 & 3 & 4 & \\
\hline & 8. Avoiding situations that make you anxious? & 0 & 1 & 2 & 3 & 4 & \\
\hline \multirow[t]{2}{*}{ V. } & 9. Unexplained aches and pains (e.g., head, back, joints, abdomen, legs)? & 0 & 1 & 2 & 3 & 4 & \\
\hline & 10. Feeling that your illnesses are not being taken seriously enough? & 0 & 1 & 2 & 3 & 4 & \\
\hline VI. & 11. Thoughts of actually hurting yourself? & 0 & 1 & 2 & 3 & 4 & \\
\hline \multirow[t]{2}{*}{ VH. } & $\begin{array}{l}\text { 12. Hearing things other people couldn't hear, such as voices even when no } \\
\text { one was around? }\end{array}$ & 0 & 1 & 2 & 3 & 4 & \\
\hline & $\begin{array}{l}\text { 13. Feeling that someone could hear your thoughts, or that you could hear } \\
\text { what another person was thinking? }\end{array}$ & 0 & 1 & 2 & 3 & 4 & \\
\hline VIII. & 14. Problems with sleep that affected your sleep quality over all? & 0 & 1 & 2 & 3 & 4 & \\
\hline IX. & $\begin{array}{l}\text { 15. Problems with memory (e.g., learning new information) or with location } \\
\text { (e.g., finding your way home)? }\end{array}$ & 0 & 1 & 2 & 3 & 4 & \\
\hline \multirow[t]{2}{*}{$\mathrm{x}$. } & 16. Unpleasant thoughts, urges, or images that repeatedly enter your mind? & 0 & 1 & 2 & 3 & 4 & \\
\hline & $\begin{array}{l}\text { 17. Feeling driven to perform certain behaviors or mental acts over and over } \\
\text { again? }\end{array}$ & 0 & 1 & 2 & 3 & 4 & \\
\hline XI. & $\begin{array}{l}\text { 18. Feeling detached or distant from yourself, your body, your physical } \\
\text { surroundings, or your memories? }\end{array}$ & 0 & 1 & 2 & 3 & 4 & \\
\hline \multirow[t]{2}{*}{ XII. } & 19. Not knowing who you really are or what you want out of life? & 0 & 1 & 2 & 3 & 4 & \\
\hline & 20. Not feeling close to other people or enjoying your relationships with them? & 0 & 1 & 2 & 3 & 4 & \\
\hline \multirow[t]{3}{*}{ XIII. } & 21. Drinking at least 4 drinks of any kind of alcohol in a single day? & 0 & 1 & 2 & 3 & 4 & \\
\hline & 22. Smoking any cigarettes, a cigar, or pipe, or using snuff or chewing tobacco? & 0 & 1 & 2 & 3 & 4 & \\
\hline & $\begin{array}{l}\text { 23. Using any of the following medicines ON YOUR OWN, that is, without a } \\
\text { doctor's prescription, in greater amounts or longer than prescribed [e.g. } \\
\text { painkllers (like Vicodin), stimulants (like Ritalin or Adderall), sedatives or } \\
\text { tranquilizers (like sleeping pills or Valium), or drugs like marijuana, cocaine } \\
\text { or crack, club drugs (like ecstasy), hallucinogens (like LSD), heroin, } \\
\text { inhalants or solvents (like glue), or methamphetamine (like speed)]? }\end{array}$ & 0 & 1 & 2 & 3 & 4 & \\
\hline
\end{tabular}


APPENDIX K

\section{Patient Registration Form}




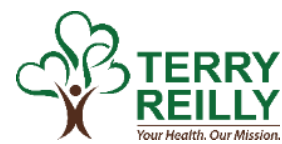

Terry Reilly Health Services does not discriminate in its services, treatment, program, activities or employment regardless of race, color, religion, national origin, age, physical or mental disability, veteran status, or sex, including gender identify and sexual orientation.

PATIENT REGISTRATION FORM

PATIENT INFORMATION

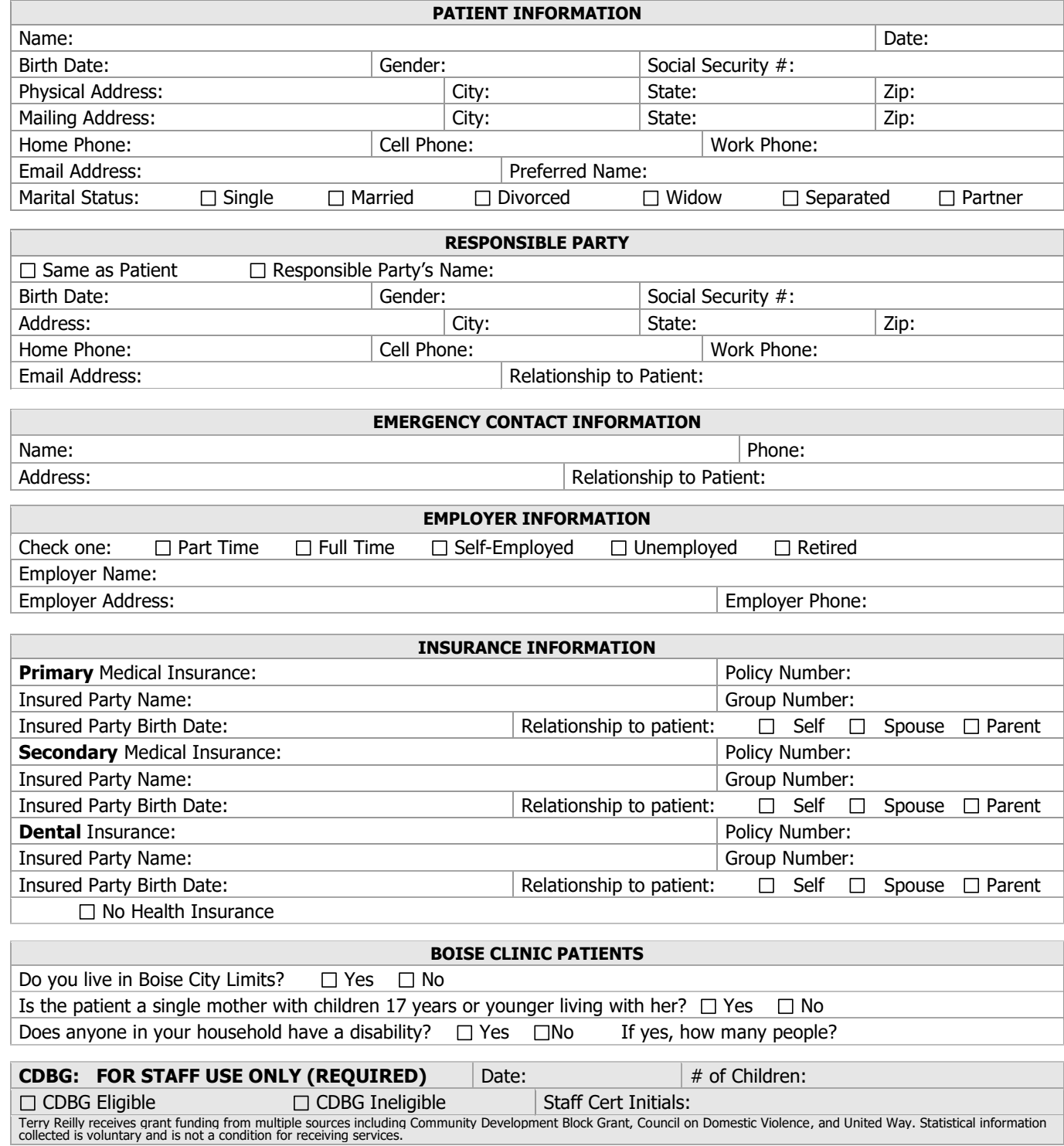


As a Federally Qualified Health Center, we are required to collect the following information for statistical purposes only. No individual information is submitted. Your cooperation helps us improve healthcare for all.

\begin{tabular}{|c|c|c|c|}
\hline \multirow{2}{*}{ Family Income } & \multicolumn{3}{|c|}{ Our annual household income before taxes is: $\$ \_$_ There are ___ people in my household. } \\
\hline & \multicolumn{3}{|c|}{ Check here if you decline to provide income information: $\square$} \\
\hline Ethnicity & Are you Hispanic/Latino? & $\square$ Yes & No \\
\hline Race & \multicolumn{3}{|c|}{$\begin{array}{llll}\square \text { White } \quad \square \text { Black/African American } & \square \text { Asian } & \square \text { Hawaiian Native } & \square \text { Pacific Islander } \\
\square \text { American Indian/Alaska Native } & \square \text { Other }\end{array}$} \\
\hline Language & \multicolumn{3}{|l|}{ What is your preferred language, including sign language? } \\
\hline \multirow[t]{3}{*}{ Farmworkers } & $\begin{array}{l}\text { In the past two years, have you or a member of your family worked in } \\
\text { Agriculture (fields, orchards, etc.) as the primary source of income? }\end{array}$ & $\square$ Yes & $\square$ \\
\hline & If yes, does this person change residence as part of his work? & $\square$ Yes & $\square$ \\
\hline & $\begin{array}{l}\text { Have you or a member of your family stopped migrating to work in Agriculture } \\
\text { due disability or old age? }\end{array}$ & $\square$ Yes & $\square \quad$ No \\
\hline Veterans & Are you a Veteran? & $\square$ Yes & $\square$ \\
\hline $\begin{array}{l}\text { Sexual } \\
\text { Orientation }\end{array}$ & \multicolumn{3}{|l|}{$\begin{array}{l}\square \text { Straight } \square \text { Lesbian, Gay or Homosexual } \square \text { Bisexual } \square \text { Other } \square \text { Unknown } \\
\square \text { Choose not to disclose }\end{array}$} \\
\hline $\begin{array}{l}\text { Gender } \\
\text { Identity }\end{array}$ & \multicolumn{3}{|c|}{$\begin{array}{l}\square \text { Male } \square \text { Female } \square \text { Transgender (Male/Female to Male) } \square \text { Transgender (Female/ Male to Female) } \\
\square \text { Other } \quad \square \text { Unknown } \square \text { Choose not to disclose }\end{array}$} \\
\hline
\end{tabular}

\begin{tabular}{l|l|l|l|l}
\hline Reduced Fees: & Are you interested in applying for our reduced fees (even if you are insured)? & $\square$ Yes & $\square$ No
\end{tabular}

\section{HEALTHCARE FOR THE HOMELESS}

If you do not own a home or rent, how would you describe your living arrangements?

I am temporarily living in: $\square$ Shelter $\quad \square$ Transitional Housing $\quad \square$ Street/Car/Camping $\square$ Drug Treatment Center $\square$ Friends/Relative - How long? $\square$ Other

\section{ACKNOWLEDGEMENTS}

Consent: I give consent for Terry Reilly to conduct a medical, dental, and/or mental health evaluation and make treatment recommendations for myself or my dependent. I further acknowledge I have been given the opportunity to read and understand the general consent to treatment policy and I agree with its content.

Financial Responsibility/Release of Information: I understand that I am responsible for all charges incurred, including deductibles, co-payments, and non-covered services. I understand that any payment made today is applied to balance and may not cover all the services I receive. I understand that Terry Reilly may bill my insurance as a courtesy to me, and I authorize the release of any medical, dental, or mental health information necessary to process my insurance claim. I also authorize payment of medical, dental, and/or mental health benefits to Terry Reilly. Some insurance policies require compliance with additional requirements such as pre-authorizations or Healthy Connection referrals. I Som to cooperate with the efforts and understand that I am responsible for all non-covered expens. Healthy accounts may be turned to collections, epported to the Credit Bur that if I apply for special programs or other assistance, my information may be shared with those programs and their auditors. Accuracy and Truthfulness of Information: The information I have provided is complete and accurate. I understand intentionally providing false information may exclude me from services at Terry Reilly, and I may be billed for discounts received under false pretenses. Patient Rights and Responsibilities: I have been given access to, and may have a copy of, the Terry Reilly Patient Rights and Responsibilities. If I believe these rights have been violated, I may file a complaint.

Notice of Privacy Practices: I have been given access to, and may have a copy of, the Terry Reilly Notice of Privacy Practices. If I choose not to, or am unable, to sign, a staff member will sign indicating he or she has provided me with access to a copy of this Notice.

Health information: Your health information may be shared across our dental, medical and behavioral health divisions.

Idaho Health Data Exchange: Terry Reilly is a proud partner with IHDE to provide effective coordination of your health care services.

This is a secure statewide internet-based health information exchange with the goal of improving the quality and coordination of health care in Idaho.

Sliding Fee: Terry Reilly Health Services may access my information from the Idaho Department of Health and Welfare's Partner Data Access Portal (PDAP) to determine my eligibility for discounts on healthcare.

Patient/Representative Signature

Date

If Representative, Relationship to Patient: 
APPENDIX L

IRB Exemption Letter 
$$
\boldsymbol{B}
$$$$
\text { BOISE STATE UNIVERSITY }
$$

RESEARCH AND ECONOMIC DEVELOPMENT

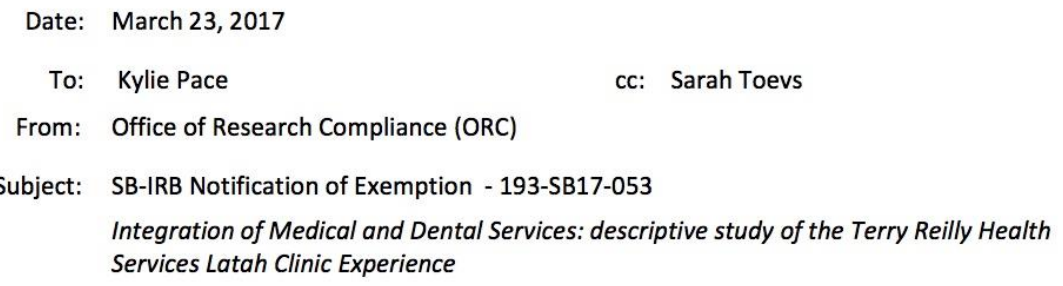

The Boise State University ORC has reviewed your protocol application and has determined that your research is exempt from further IRB review and supervision under 45 CFR 46.101(b).

Protocol Number: 193-SB17-053

Approved: $3 / 23 / 2017 \quad$ Application Received: 3/7/2017

Review: Exempt

Category: 2

This exemption covers any research and data collected under your protocol as of the date of approval indicated above, unless terminated in writing by you, the Principal Investigator, or the Boise State University IRB. All amendments or changes (including personnel changes) to your approved protocol must be brought to the attention of the Office of Research Compliance for review and approval before they occur, as these modifications may change your exempt status. Complete and submit a Modification Form indicating any changes to your project.
\end{abstract}

Annual renewals are not required for exempt protocols. When the research project is completed, please notify our office by submitting a Final Report. The exempt status expires when the research project is completed (closed) or when the review category changes as described above.

All forms are available on the ORC website at http://goo.gl/D2FYTV

Please direct any questions or concerns to ORC at 426-5401 or humansubjects@boisestate.edu.

Thank you and good luck with your research.

Office of Research Compliance 